Illinois State University

ISU ReD: Research and eData

Theses and Dissertations

$5-11-2016$

\title{
A New Approach To Measuring Helicopter Parenting: The Multidimensional Helicopter Parenting Scale
}

Hayley Love

Illinois State University, hlove@ilstu.edu

Follow this and additional works at: https://ir.library.illinoisstate.edu/etd

Part of the Psychology Commons

\section{Recommended Citation}

Love, Hayley, "A New Approach To Measuring Helicopter Parenting: The Multidimensional Helicopter Parenting Scale" (2016). Theses and Dissertations. 583.

https://ir.library.illinoisstate.edu/etd/583

This Thesis is brought to you for free and open access by ISU ReD: Research and eData. It has been accepted for inclusion in Theses and Dissertations by an authorized administrator of ISU ReD: Research and eData. For more information, please contact ISUReD@ilstu.edu. 


\title{
A NEW APPROACH TO MEASURING HELICOPTER PARENTING: THE MULTIDIMENSIONAL HELICOPTER \\ PARENTING SCALE
}

\author{
Hayley Love
}

\section{Pages}

The purpose of this study was to find a way to measure helicopter parenting that directly reflects its conceptual definition that has been established by Cline and Fay (1990). Literature has pointed to several parenting dimensions that constitute helicopter parenting (Kins \& Soenens, 2013; Klein \& Pierce, 2009). Rather than looking at helicopter parenting as a qualitatively distinct approach to parenting, this study attempted to show that parenting dimensions established in existing literature are what constitutes helicopter parenting. Helicopter parenting should be looked at as falling on an extreme end of the spectrum of different parenting dimensions. A total of 500 participants were recruited for this study, 352 of which were retained with a majority identifying as Caucasian and female. Specifically, measures of parental overprotection, care, psychological control, behavioral control, involvement, responsiveness, autonomy support, and a separate measure that has been created to look at helicopter parenting were 
used to evaluate participants' reported experience of parenting behaviors. Measures of coping efficacy, interpersonal dependency, and psychological well-being were used to evaluate outcomes associated with helicopter parenting. The results indicated that the proposed measure of helicopter parenting was found to be both a reliable and valid measure of this phenomenon. The study supported the multidimensional aspect of the proposed measure and further suggests that helicopter parenting behaviors should be looked at separately in regards to outcomes associated with this phenomenon.

KEYWORDS: College Student Development, Exploratory Factor Analysis, Helicopter Parenting, Measurement Development, Measuring Helicopter Parenting, Parent-Adult Child Relationships, Parenting Behaviors, Psychological Well-Being 


\title{
A NEW APPROACH TO MEASURING HELICOPTER PARENTING:
}

\section{THE MULTIDIMENSIONAL HELICOPTER}

PARENTING SCALE

\author{
HAYLEY LOVE
}

A Thesis Submitted in Partial Fulfillment of the Requirements for the Degree of

MASTER OF SCIENCE

Department of Psychology

ILLINOIS STATE UNIVERSITY

2016 
C 2016 Hayley Love 


\section{A NEW APPROACH TO MEASURING HELICOPTER PARENTING:}

\section{THE MULTIDIMENSIONAL HELICOPTER}

PARENTING SCALE

HAYLEY LOVE

COMMITTEE MEMBERS:

Rocio Rivadeneyra, Chair

Joel Schneider 


\section{ACKNOWLEDGMENTS}

\section{I would like to thank my committee Drs. Rocio Rivadeneyra and Joel Schneider}

for the support and encouragement throughout this process.

H. L. 


\section{CONTENTS}

Page

ACKNOWLEDGMENTS

$\begin{array}{ll}\text { CONTENTS } & \text { ii }\end{array}$

TABLES $\quad$ V

CHAPTER

I. PARENTAL INVOLVEMENT AMONG COLLEGE STUDENTS 1

II. LITERATURE REVIEW 2

Theory of Student Development 2

Helicopter Parenting $\quad 5$

$\begin{array}{ll}\text { Psychological Well-Being } & 6\end{array}$

Parenting Dimensions Related to Helicopter Parenting 7

Helicopter Parenting as a Distinct Parenting Dimension? 11

Measures of Helicopter Parenting 21

III. THE PROPOSED STUDY 22

$\begin{array}{ll}\text { Exploratory Analyses } & 23\end{array}$

Hypothesis $1 \quad 23$

Hypothesis $2 \quad 24$

Hypothesis 3

Hypothesis $4 \quad 25$

Hypothesis 5

Hypothesis $6 \quad 25$

Hypothesis 7

Helicopter Parenting and Outcome Measures 26

Hypothesis $8 \quad 26$

Hypothesis $9 \quad 27$

Hypothesis $10 \quad 27$ 
IV. METHODS 28

$\begin{array}{ll}\text { Participants } & 28\end{array}$

$\begin{array}{ll}\text { Measures } & 28\end{array}$

Demographics $\quad 28$

Helicopter Parenting 28

Parental Psychological Control, Behavioral Control,

Responsiveness, and Autonomy Support $\quad 29$

Parental Involvement $\quad 30$

Parental Care and Overprotection $\quad 30$

Coping Efficacy 31

Interpersonal Dependency $\quad 32$

Psychological Well-Being $\quad 32$

$\begin{array}{ll}\text { Procedure } & 33\end{array}$

V. RESULTS 34

Exploratory Factor Analysis $\quad 34$

Bivariate Correlation Analyses 43

Multiple Regression 46

VI. DISCUSSION 52

Reliability of Proposed Measure $\quad 52$

Validity of Proposed Measure $\quad 52$

Hypothesis 1

Hypothesis $2 \quad 53$

Hypothesis $3 \quad 54$

Hypothesis $4 \quad 55$

Hypothesis 5

Hypothesis $6 \quad 56$

Hypothesis $7 \quad 57$

Hypothesis $8 \quad 57$

Hypothesis $9 \quad 58$

Hypothesis 10

Limitations 61

Data Collection Error $\quad 61$

Measurement Analysis Limitations $\quad 61$

Sample Limitations $\quad 62$

Strengths, Implications and Future Directions 62 
REFERENCES 


\section{TABLES}

Table

Page

1. Factor Loadings and Communalities Based on a Principle Axis Factor Analysis with Promax Rotation for 49 Items from the Survey $(\mathrm{N}=352)$

2. Bivariate Correlations Between the Eight Helicopter Parenting Factors $(\mathrm{N}=352)$

3. Descriptive Statistics of the Hierarchical Linear Regression (Parenting Measures and Outcomes Only)

4. Regression of Demographic (Control) and Parenting (Predictor) Variables Predicting Interpersonal Dependency $(\mathrm{N}=329)$

5. Regression of Demographic (Control) and Parenting (Predictor) Variables Predicting Coping Efficacy $(\mathrm{N}=327)$

6. Regression of Demographic (Control) and Parenting (Predictor)

Variables Predicting Psychological Well-Being $(\mathrm{N}=329)$ 


\section{CHAPTER I}

\section{PARENTAL INVOLVEMENT AMONG COLLEGE STUDENTS}

In recent years, parental involvement in emerging adults' life in college has increased in the U.S. (Wartman \& Savage, 2008). This increased involvement has been attributed to the "baby-boomer" generation, cost of college, expansion of communicative technology, changes in parenting, and individual differences (Wartman \& Savage, 2008). Many studies have shown that increased parental involvement can provide many advantages and disadvantages to students' development in college (Schiffrin et al., 2014). Thus, the level of parental involvement in U.S. college students has been an important focus in recent research (Wartman \& Savage, 2008). Over-involvement in emerging adulthood has been shown to hinder autonomy development in college students (Chickering \& Reisser, 1993). Theory has pointed to the importance of autonomy development in college students as this is a necessary component of emotional adjustment in college (Wartman \& Savage, 2008). 


\section{CHAPTER II}

\section{LITERATURE REVIEW}

\section{Theory of Student Development}

Chickering and Reisser (1993) described the components of student development and transition into adulthood that occurs during college as having seven major vectors, or tasks: "developing competence, managing emotions, moving through autonomy toward interdependence, developing mature interpersonal relationships, establishing identity, developing purpose, and developing integrity." These vectors provide foundational framework through which we are able to view students' psychological development as they continue to develop their identity through the college experience and make a final transition from adolescence to adulthood (Chickering \& Reisser, 1993).

Originally established in 1969 and revised in 1993, Chickering and Reisser's theory of identity development in college has stressed the importance of particular tasks that facilitate the transition from adolescence to adulthood in a college setting. "Moving through autonomy and toward interdependence" is one of the seven vectors of Chickering and Reisser's theory of identity development of college students. It has been previously theorized that separation and individuation is vital in the development of identity (Chickering \& Reisser, 1993). Chickering and Reisser (1993) identify three components involved in moving through autonomy and toward interdependence: (1) emotional independence, defined as no longer needing approval from others; (2) instrumental 
independence, defined as confidence in taking on problems, activities, and pursuing opportunity independently, and (3) interdependence, which is the "awareness of one's place in and commitment to the welfare of the larger community." Originally, in 1969, Chickering did not place emphasis on developing interdependence (Chickering \& Reisser, 1993). Since then, Chickering and Reisser (1993) have established the importance of being independent as well as recognizing the necessity of other people in society and the purposes they serve.

In the terms of a Western/individualistic cultural view, Chickering and Reisser (1993) emphasizes that the first step toward emotional independence requires some type of separation from parents and increased need of support from peers and institutions. Students' increased independent decision-making has been progressively associated with students' development into functional adults with a will to survive and succeed (Chickering \& Reisser, 1993). It has been found that emerging adults have developed skills to manage anxiety and build self-confidence by having parents that promote the development of autonomy at home (Chickering \& Reisser, 1993). So even in cases where students are still living at home with parents, developing emotional independence has been shown to provide positive outcomes.

The second component of moving through autonomy and towards interdependence, instrumental independence, is broken down into two major components: the ability to be self-sufficient and on one's own and versatility of leaving one place and functioning just as well in another (Chickering \& Reisser, 1993). Those with instrumental independence are able to manipulate their environment and structure their lives to meet their daily needs and responsibilities with little support from others (Chickering \& 
Reisser, 1993). Positive collegiate outcomes require students to be able to be productive and function on their own, especially in cases where they are attending college a distance away from parents. It has been found that instrumental autonomy is positively associated with intellectual competence (Chickering \& Reisser, 1993). Students who develop emotional and instrumental independence have been found to build great coping skills (Chickering \& Reisser, 1993). Segrin, Woszidlo, Givertz, and Montgomery (2013) found that over-parenting was associated with adult children's reports of poor coping skills; these poor coping skills were found to be strongly associated with reports of anxiety and stress. Segrin and colleagues' (2013) results link back to the importance of instrumental autonomy as parents who do not allow their offspring the opportunity to build their instrumental independence may not build great coping skills, thus leading to poor outcomes.

Interdependence is the final component of Chickering and Reisser's (1993) vector, "moving through autonomy and towards interdependence." Chickering and Reisser (1993) described that interdependence cannot be achieved until a certain level of independence is reached. In a western/individualistic culture, individuals who develop interdependence realize that the world is made up of many autonomous individuals (Chickering \& Reisser, 1993). This realization of other autonomous individuals facilitates the understanding of rules and responsibilities as well as respect for others (Chickering \& Reisser, 1993). Understanding the autonomy of others is another way in which individuals learn to survive and succeed. These components involved in moving through autonomy toward interdependence show that going through this vector is important to 
reach developmental milestones that support psychological well-being and college adjustment.

\section{Helicopter Parenting}

This autonomy development typically occurs when students and their parents start to develop an adult-adult relationship as opposed to a parent-child relationship. The transition from a parent-child relationship to an adult-adult relationship may provide strong cues to the student that they are making final transitions from adolescence to adulthood. To move through autonomy and toward interdependence, parents need to reduce the amount of control and involvement they implement in the relationship with their offspring (Chickering \& Reisser, 1993). In recent years, there has been concern that some parents do not make this parent-child relationship to adult-adult relationship transition when their offspring enters college (Schiffrin et al., 2014). Some parents may continue to be heavily involved and attempt to control their offspring's life even though they are considered legal adults at the age of 18 (Schiffrin et al., 2014).

This phenomenon of over-controlling and over-involved parenting has been labeled "helicopter parenting" by the popular press and more recently by scholars and has been associated with negative outcomes in college students (Schiffrin et al., 2014). The term "helicopter parenting" was first introduced by Cline and Fay in 1990. In their book, Parenting Teens with Love \& Logic, Cline and Fay (2006) described helicopter parenting as parents who hovered around their children to protect them "whenever a problem arises." Cline and Fay (2006) explained that helicopter parents behave this way because "they confuse love, protection, and caring" by not allowing their child to fail in any aspect of their child's life. Helicopter parenting represents parental concern taken to a 
dysfunctional level including examples such as calling professors to demand a better grade for their offspring, attending job fairs for their offspring, doing their offspring's homework for them, or other actions that take the responsibility and demands away from the child and place it on the parents (Bradley-Giest \& Olson-Buchanan, 2014; LeMoyne \& Buchanan, 2011).

\section{Psychological Well-Being}

Even though "helicopter parenting" has been of increasing concern among college administrators, it is implied that parents only are doing this because they are concerned for their offspring's well-being (Cline \& Fay, 2006; Padilla-Walker \& Nelson, 2012). Helicopter parents aim to prevent their offspring from failing at any aspect of their life, yet ironically by doing this, parents may be undermining their offspring's well-being. According to Ryff (1989), psychological well-being is one recognizing their true human potential, "which reaches beyond happiness in that it measures a person's perceptions of potential, thriving, and functioning." Ryff's (1989) theory of psychological well-being consists of six dimensions that attempt to describe how well an individual succeeds and survives in a challenging environment. These dimensions also are reflective of an individual's maturity (Ryff, 1989).

The first dimension of well-being is self-acceptance - vital for development, mental health, self-actualization and recognition of mistakes and limitations - and is described as the satisfaction of one's self (Ryff, 1989). Positive relations assess an individual's ability to have functional relationships (Ryff, 1989). Autonomy is an individual's ability to function alone (Ryff, 1989). Environmental mastery is the next dimension explained by Ryff (1989) and is described as an individual's ability to 
successfully participate in society, while purpose in life, is the "perception that one has goals and a sense of directedness (Ryff, 1989). The final dimension Ryff (1989) describes is personal growth, which is the perception of one's potential and ability to continuously grow and develop as a person.

\section{Parenting Dimensions Related to Helicopter Parenting}

To assess psychological well-being and college adjustment associated with parent involvement, Bradley-Giest and Olson-Buchanan (2014) thought there is a distinction between involvement and over-parenting. Bradley-Giest and Olson-Buchanan (2014) made a point that parental involvement and over-parenting are not mutually exclusive, those who over-parent are involved parents but not all parents who are involved are overparenting. Bradley-Giest and Olson-Buchanan (2014) distinguished over-parenting and parental involvement by the degree in which certain behaviors are exhibited. Parents who are involved may suggest their child to take action on certain situations like talking to the professor about their grade, whereas parents who are over-parenting will call the professors and handle the situation themselves (Bradley-Giest and Olson-Buchanan, 2014). The way that Bradley-Giest and Olson-Buchanan (2014) try to distinguish parental involvement from over-parenting seems as though over-parenting is a result of very high levels of parental involvement. Because parents have to be involved in their offspring's life to be considered over-parenting, it would make sense to look at parental involvement as a dimension of over-parenting.

Four hundred and eighty-two undergraduates participated in the study, with fairly equal gender distribution (55 percent male) and had a mean age of 23.04 (Bradley-Giest \& Olson-Buchanan, 2014). These participants were mainly college seniors and would be 
expecting to receive their degree within the next six to 18 months (Bradley-Giest \& Olson-Buchanan, 2014). The sample was also fairly diverse containing a portion of Asian, Black, Hispanic, Native American, and White participants (19.5\%, 5.6\%, 30.7\%, 3.1\%, 40.5\%, respectively; Bradley-Giest \& Olson-Buchanan, 2014).

Bradley-Giest and Olson-Buchanan (2014) were interested in looking at students' reports of self-efficacy. Specifically, Bradley-Giest and Olson-Buchanan (2014) used the self-efficacy scale (Sherer, 1982), which was split into general and social self-efficacy. Students reported on their parents' involvement in their lives. The parental involvement scale was created specifically for this study, which contained nine items that assessed the frequency of parents' involvement with one's school and social life (Bradley-Giest \& Olson-Buchanan, 2014). An example of an item on the parental involvement scale was, How often do your parents/guardians ask you about your grades? The over-parenting scale was also created specifically for this study and contained five items looking at whether students felt that their parents were too involved in their lives (Bradley-Giest \& Olson-Buchanan, 2014). An example of an item on the over-parenting scale was, $M y$ parents/guardians have interfered in my life when I wish they wouldn't have. A 12-item scale was created to look at maladaptive responses to the workplace scenarios that were presented (Bradley-Giest \& Olson-Buchanan, 2014). Students were given four workplace scenarios to evaluate and rated the likelihood that they would take each of the actions listed (Bradley-Giest \& Olson-Buchanan, 2014). Finally, students' classroom outcomes were assessed by obtaining peer-evaluation ratings from other students and self-reported GPA (Bradley-Giest \& Olson-Buchanan, 2014). 
Bradley-Giest and Olson-Buchanan (2014) found that student reported parental involvement was positively associated with parental education, when the guardians are the student's biological parents, and when the student is a younger female compared to guardians who are not the student's biological parents and when the student is older or male. Over-parenting was predicted by the student living with parents and having fewer siblings (Bradley-Giest \& Olson-Buchanan, 2014). These findings are purely correlational and do not provide directionality (Bradley-Giest \& Olson-Buchanan, 2014). Over-parenting with fewer offspring made sense to the researchers in a practical and evolutionary way (Bradley-Giest \& Olson-Buchanan, 2014). Parents who have less offspring have more time to devote to each offspring and have more at stake in terms of the survival and well-being of the offspring (Bradley-Giest \& Olson-Buchanan, 2014). Exploratory analyses showed that Asian students were more likely than others to report over-parenting (Bradley-Giest \& Olson-Buchanan, 2014). White students reported higher than Hispanic students in terms of levels of parental involvement (Bradley-Giest \& Olson-Buchanan, 2014). Analyses also revealed that parental involvement was positively associated with students' social and general self-efficacy, while over-parenting was negatively associated with these two outcomes (Bradley-Giest \& Olson-Buchanan, 2014). Parental involvement was found to predict students' intentions to attend graduate school (Bradley-Giest \& Olson-Buchanan, 2014). In regards to academic performance, there were no significant findings between parental involvement/over-parenting and selfreported GPA or peer-evaluations (Bradley-Giest \& Olson-Buchanan, 2014).

Finally, the analyses addressing work-related behaviors showed that overparenting predicted maladaptive responses to workplace scenarios (Bradley-Giest \& 
Olson-Buchanan, 2014). Interestingly, students, who reported that their parents overparented, endorsed solutions that displayed dependence on others rather than taking on responsibility in the workplace (Bradley-Giest \& Olson-Buchanan, 2014). Self-efficacy was also found as a mediator between over-parenting and maladaptive workplace responses, which implies that the reason over-parenting is associated with maladaptive workplace responses is because over-parenting is also associated with lower self-efficacy (Bradley-Giest \& Olson-Buchanan, 2014).

Even though causal statements cannot be made as to whether over-parenting influenced lower levels of social and general self-efficacy, the findings in this study provide evidence that warrant research to further clarify whether the two constructs (parental involvement, over-parenting) are truly independent of each other. The questionnaires were reported to be significantly correlated; however little detail was reported on how the factor analysis supported the distinction between the two constructs (Bradley-Giest \& Olson-Buchanan, 2014).

Klein and Pierce (2009) looked at parental care (the amount of affection shown to the child) and overprotection (parental smothering and over-involvement) in relation to students' college adjustment. Klein and Pierce (2009) hypothesized that students who received high levels of parental care and low levels of parental overprotection would adjust to college better than students who do not receive this type of "optimal parenting." The study contained 83 college students, primarily white and female (76\% Caucasian, 62 women) with a mean age of 20.2 (Klein \& Pierce, 2009). The College Adjustment Scales was used to evaluate perceived adjustment to college (Anton \& Reed, 1991). There were nine subscales that measured anxiety, depression, suicidal ideation, substance abuse, self- 
esteem problems, interpersonal problems, family problems, academic problems, and career problems (Klein \& Pierce, 2009). The Parental Bonding Instrument is a 25-item scale that was used to measure the amount of care (12 items; i.e., Was affectionate to me.) and overprotection (13 items; i.e., Tried to control everything I did.) perceived by the student (Parker, Tupling, \& Brown, 1979). Students filled out this instrument separately for both mother and father, indicating the degree to which these statements were like or unlike their parents.

Results showed that higher parental care and lower parental overprotection was associated with positive college adjustment including fewer academic, anxiety, interpersonal, depression, self-esteem, and family problems (Klein \& Pierce, 2009). Klein and Pierce (2009) discussed that these findings may be due to the fact that overprotective parents may hinder autonomy development in their offspring that is vital for self-care. This relates to the study by Bradley-Giest and Olson-Buchanan (2014) as they found that over-parenting was associated with lower levels of social and general self-esteem. The findings by Klein and Pierce (2009) also reinforce the idea that there is an "optimal" form of parenting (higher parental care and lower parental overprotection). Looking at overprotection and care versus involvement and over-involvement both provide interesting views on assessing this optimal form of parenting (Bradley-Giest \& OlsonBuchanan, 2014; Klein \& Pierce, 2009).

\section{Helicopter Parenting as a Distinct Parenting Dimension?}

LeMoyne and Buchanan's (2011) study specifically examined psychological wellbeing and its association to over-parenting. The impact of helicopter parenting on college students' well-being and whether helicopter parenting is related to taking prescription 
medication for anxiety or depression and substance abuse were the primary research questions (LeMoyne \& Buchanan, 2011). There were 317 college students under the age of 25 that participated in the study (LeMoyne \& Buchanan, 2011). LeMoyne and Buchanan (2011) developed a helicopter parenting scale that consisted of 10 items, assessing how controlling and transactional respondents felt their parents were while growing up. During the development of the helicopter parenting measure, LeMoyne and Buchanan (2011) stated that "It is hypothesized that helicopter parenting represents a collection of tendencies that constitute appropriate parenting characteristics taken to an inappropriate degree", meaning that they believed helicopter parenting is consisted of multiple parenting dimensions. This provides evidence in their belief that supports the multi-dimensionality of helicopter parenting. An example item from LeMoyne and Buchanan's (2011) measure was, I sometimes felt that my parents didn't feel I could make my own decision; this item reflects how helicopter parents show a lack of autonomy supportiveness. A 10-item survey may not be able to accurately measure the parenting dimensions involved in helicopter parenting, as it may potentially leave out aspects of parenting that are prominent in this phenomenon. A shortened version of Ryff's global well-being was used to measure respondents' psychological well-being (LeMoyne \& Buchanan, 2011). General demographics, student grade point average, socioeconomic background, prescription drugs, and pain pill consumption was also assessed (LeMoyne \& Buchanan, 2011).

Results showed that students, who reported parents as helicopter parenting, reported lower levels of overall well-being, were more likely to report having prescriptions for anxiety/depression, and were more likely to report taking pain pills 
without a prescription (LeMoyne \& Buchanan, 2011). LeMoyne and Buchanan's (2011) results related to the results of Klein and Pierce (2009) as the latter found that higher parental care and less parental control were associated with positive college adjustment including specific measures evaluating anxiety and depression. This study extends from the literature as it attempts to create a measure specifically assessing the phenomenon of helicopter parenting, which encompasses type and amount of parental involvement; however, it brings up questions as to whether helicopter parenting should be considered a distinct construct from other parenting dimensions. LeMoyne and Buchanan's (2011) measure asked participants to reflect on their past experiences. This also brings up possible issues with the way in which LeMoyne and Buchanan (2011) measured helicopter parenting because they are technically not assessing the participants' current experience of helicopter parenting. Helicopter parenting is defined as parents continual efforts to prevent their child from failure even at an older age when it may not be appropriate (i.e., filling out job applications for one's offspring); LeMoyne and Buchanan (2011) may have benefited from having participants report on their current experiences with parents.

Schiffrin et al. (2014) also created a measure assessing parenting behaviors in relation to the phenomenon of helicopter parenting. The purpose of Schiffrin et al.'s (2014) study was to examine how parenting behaviors affect college students' psychological well-being. Consistent with other literature, they hypothesized that helicopter parenting would interfere with psychological well-being (specifically autonomy, competence, and relatedness) and this interference would affect college students' mental health (Schiffrin et al., 2014). Participants were 297 undergraduate 
students primarily white (84.8\%) and female (88\%) with an age range of 18 to 23 (Schiffrin et al., 2014).

The measure assessing helicopter parenting was comprised of 20 behaviors that have been associated with helicopter parenting in previous literature; 7 items were added that assessed behaviors associated with autonomy supportive parenting that have also been supported in the literature (Schiffrin et al., 2014). The measure of helicopter parenting focused on parental behaviors to control their college-aged children's behavior or take actions for them (i.e., calling a professor to discuss student's grades) whereas, the measure of autonomy supportive parenting focused on parental encouragement of their offspring to handle situations on their own (i.e., My mother encourages me to keep a budget and manage my own finances) (Schiffrin et al., 2014). After an exploratory factor analysis a total of nine items were retained assessing helicopter parenting and a total of six items were retained that assessed autonomy supportive parenting (Schiffrin et al., 2014). It is evident that Schiffrin and colleagues (2014) believe that helicopter parenting is somewhat multidimensional as they created two subscales of helicopter parenting: parental control and parental autonomy support. However, there may be already existing scales that measure these two dimensions that may have more reliability and validity. Another question about Schiffrin and colleagues' (2014) helicopter parenting measure is that whether these two parenting dimensions are the only dimensions that constitute helicopter parenting. As was presented in Klein and Pierce's (2009) high parental overprotection may be a possible helicopter parenting dimension, as it reflects characteristics of a parent who is protecting their child from any form of failure, which is described as the phenomenon of helicopter parenting. If helicopter parenting is truly multidimensional, 
it is unclear as to how many dimensions will help create a completely comprehensive view of the phenomenon.

Aside from the development of the helicopter parenting measure, Schiffrin and colleagues (2014) also used the Basic Needs Satisfaction in General Scale (BNSG-S) to measure participants' autonomy, competence, and relatedness. The Satisfaction with Life Scale (SWLS) was used to measure participants' overall life satisfaction (Schiffrin et al., 2014). To assess mental health, Schiffrin and colleagues (2014) used the Center for Epidemiologic Studies Depression Scale (CES-D) and the anxiety subscale of the Hospital Anxiety and Depression scale (HAD).

Schiffrin and colleagues (2014) found that participants, who reported that their parents displayed helicopter parenting behaviors, reported higher levels of depression and lower levels of life satisfaction. However, they did not find a relationship between helicopter parenting and anxiety (Schiffrin et al., 2014). They also found that helicopter parenting was associated with lower levels of autonomy, competence, and relatedness (Schiffrin et al., 2014). Participants who reported lower levels of autonomy also reported higher levels of depression (Schiffrin et al., 2014). Participants who reported lower levels of competence were more likely to report higher levels of depression and lower levels of life satisfaction (Schiffrin et al., 2014). Also, Schiffrin and colleagues (2014) found that helicopter parenting had an indirect effect on depression and life satisfaction through competence and an indirect effect on depression through autonomy. These results are consistent with the findings by LeMoyne and Buchanan (2011) as they found that higher levels of helicopter parenting were associated with having prescription medication for depression. 
Padilla-Walker and Nelson (2012) collected data from undergraduate college students and at least one parent. The purpose of their study was to establish a new measure of helicopter parenting that did not overlap with other forms of parental control and parenting dimensions, as well as examine parenting in relation to self-worth, school engagement, and perceptions of adulthood and identity (Padilla-Walker \& Nelson, 2012). The sample consisted of 438 ethnically diverse undergraduates ( $73 \%$ female) and at least one of their parents.

Padilla-Walker and Nelson's (2012) measure assessing helicopter parenting contained five items that assessed the degree of parental decision-making for their offspring reaching adulthood. My parent solves any crisis or problem I might have, is an example found on the helicopter parenting measure (Padilla-Walker \& Nelson, 2012). A five-item measure of behavioral control was used to assess the degree to which parents control their offspring's friends, money or activities (Padilla-Walker \& Nelson, 2012). My parent tries to set rules about what I do with my free time, is an example of an item found on the behavioral control measure (Padilla-Walker \& Nelson, 2012). A four-item measure of psychological control was used to assess the degree of psychological controlling parents implement on their emerging adult offspring (Padilla-Walker \& Nelson, 2012). My parent will avoid looking at me when I disappoint her/him, is an example of an item found on the psychological control measure. Parenting was also assessed using the warmth, involvement, and autonomy support subscales of the Perception of Parents Scale: College Student Version (POPS; Grolnick, Ryan, \& Deci, 1991; Robbins, 1994). The guidance/advice, disclosure, affection, and emotional support subscales from the Social Provisions Questionnaire were used to assess the parent-child 
relationship (Carbery \& Buhrmester, 1998). Self-worth was assessed using a shortened version of the Self Perceptions Profile for College Students (Neeman \& Harter, 1986). The measure assessing school engagement was composed of three items focusing on students' commitment to education (Fredericks, Blumenfeld, \& Paris, 2005). Finally, perceptions of adulthood and identity were assessed by asking students if they believed that they had reached adulthood as well as using the Ego Identity Scale that focuses on identity in occupation, dating, and values/beliefs (Balistreri \& Busch-Rossenagel, 1995).

Padilla-Walker and Nelson (2012) only focused on parental decision-making as the sole characteristic of helicopter parenting; when regarding the definition of helicopter parenting, (parents who protect their children from failure) it seems as though parental decision-making is a good fit. However, decision-making is very multidimensional as there can be various domains in the child's life in which parental decision-making may be exercised (i.e., social activities, school involvement, athletics); does Padilla-Walker and Nelson's (2012) five-item measure fully grasp this construct? Decision-making also reflects a lack of autonomy supportiveness from the parent, thus utilizing an autonomy support measure may give a more comprehensive outlook on this dimension of helicopter parenting. Factor analyses showed that helicopter parenting was distinct from psychological and behavioral control (Padilla-Walker \& Nelson, 2012); however, all measures of parental control (helicopter parenting, psychological control, behavioral control) were shown to be interrelated. Again, this brings up the question as to whether Padilla-Walker and Nelson's (2012) measure completely grasps the multidimensionality of helicopter parenting or if combining these forms of control to measure this phenomenon may help give a more comprehensive understanding. Helicopter parenting 
was also found to be positively related to parental involvement as well as guidance, disclosure, and emotional support in parent-child relationships (Padilla-Walker \& Nelson, 2012). Consistent with previous research and theory, helicopter parenting was negatively associated with parental autonomy granting (Padilla-Walker \& Nelson, 2012). The findings by Padilla-Walker and Nelson (2012) provide further information of the phenomenon of helicopter parenting as it negatively affects autonomy development, which may lead to poor adjustment outcomes (i.e., mental health, grades, personal growth) in college students.

In one of the most recent studies that examined helicopter parenting, Odenweller, Booth-Butterfield, and Weber (2014) utilized the Helicopter Parenting Scale (HPS) developed by LeMoyne and Buchanan (2011) as well as created their own Helicopter Parenting Instrument (HPI) to account for limitations found in the HPS. LeMoyne and Buchanan's (2011) HPS consisted of seven items; whereas, the HPI contained 15 items (Odenweller, et al., 2014). Odenweller and colleagues referred to theory and literature (i.e., Padilla-Walker \& Nelson, 2012; Segrin et al., 2012) focusing on the phenomenon of helicopter parenting to create the HPI.

Odenweller and colleagues (2014) collected data from 268 participants (54.9\% female, Mage $=20.75)$. Most of the sample consisted of Caucasians (90.3\%). Besides their use of the HPI and HPS, Odenweller and colleagues (2014) measured parenting styles through the use of the Parental Authority Questionnaire - Short Version (Alkharusi, Aldhafri, Kazem, Alzubiadi, \& Al-Bahrani, 2011). This questionnaire consisted of 20 items that measure the offspring's perceived parent's parenting style. Three subscales covered three different parenting styles; seven items were on authoritarian parenting, 
seven for authoritative parenting, and six for permissive parenting. Odenweller and colleagues (2014) also used the Revised Family Communication Patterns Instrument (Ritchie \& Fitzpatrick, 1990) to measure offspring's perceived parents' conformity and conversation orientations. There were two subscales that this measure consisted of; the conformity orientation included 11 items and the conversation orientation subscale included 15 items. Odenweller and colleagues (2014) measured outcomes such as Neuroticism (12-items), interpersonal dependency (17-items), and coping efficacy (four items).

Results showed that there was a positive correlation between the HPI and HPS (Odenweller, et al., 2014). Odenweller and colleagues (2014) reported that the HPI demonstrated strong construct validity and reliability. It was also found that there was a positive relationship between helicopter parenting and conformity orientation, neuroticism, interpersonal dependency and a negative relationship between helicopter parenting and coping efficacy (Odenweller et al., 2014). Because the sample primarily consisted of Caucasian participants, the results Odenweller and colleagues (2014) found may possibly be limited to their sample. This brings up the continued question as to whether the HPI is a reliable and valid measure of the phenomenon of helicopter parenting.

Kins and Soenens (2013) study focused on parental overprotection as a form of helicopter parenting. In this study they had 581 adolescents $\left(M_{\mathrm{age}}=16\right)$ and 386 mothers (Kins \& Soenens, 2013). Kins and Soenens (2013) developed a measure of parental overprotection (35 items) that was comprised of seven subscales (anxious rearing, premature problem solving, babying, privacy invasion, pedestal - overly praising, 
hyperactivation of emotions, and external attribution). The Parental Bonding Instrument was also utilized to measure overprotection (Parker et al., 1979).

Kins and Soenens (2013) looked at parenting dimensions such as, autonomy support, psychological control, behavioral control, involvement, and responsiveness. Autonomy support and involvement was assessed using the Perceptions of Parents Scale (Grolnick et al, 1991), while psychological control, behavioral control, and responsiveness was measured using the Louvain Adolescent Perceived Parenting Scale (LAPPS; Soenens, et al., 2004). The LAPPS is comprised of four subscales measuring psychological control, behavioral control, responsiveness, and autonomy support. The subscales regarding responsiveness (i.e., My father/mother gives me a lot of care and attention), behavioral control (i.e., My father/mother insists that I must do exactly as I am told), and psychological control (i.e., My father/mother is always trying to change me) were created by taking items from the Child Report of Parental Behavior Inventory (CRPBI; Schludermann \& Schludermann, 1988). The psychological control scale also included some items from the Parenting Scales (PS; Lamborn, Mounts, Steinberg, \& Dornbusch, 1991). The autonomy support subscale (i.e., My father/mother encourages me to be independent from him) was created by taking items from the Perception of Parents Scale (POPS; Grolnick, et al., 1997).

In this study, Kins and Soenens (2013) found that overprotection of helicopter parenting reflects a pattern of low autonomy, high psychological control, high behavioral control, and moderate responsiveness and involvement. This study gives an interesting insight on the specific parenting dimensions included in the LAPPS and how they may constitute helicopter parenting. More specifically, as Klein and Pierce (2009) provided in 
their study an optimal combination of protection and care, Kins and Soenens (2013) provided information regarding a combination of varying levels of parenting dimensions that could be used to measure the multidimensional phenomenon of helicopter parenting.

\section{Measures of Helicopter Parenting}

The lack of general consensus of how to measure helicopter parenting is one of the primary concerns in the recent growing empirical literature on this topic. Some researchers have argued that helicopter parenting is distinct from other parenting dimensions such as, behavioral control, psychological control, and involvement (BradleyGiest \& Olson Buchanan, 2014; Padilla-Walker \& Nelson, 2012). Other research has shown that helicopter parenting is a combination of parenting dimensions (i.e., involvement, control, care, protection; Klein \& Pierce, 2009).

Cline and Fay (1990) described helicopter parenting as parental concern taken to a dysfunctional level to protect their child from any sign of failure. Helicopter parenting as defined by Cline and Fay (1990) should reflect parenting dimensions that have been established in previous literature (i.e., support, involvement, control) that are taken to an extreme. This view is different from other researchers who believe that helicopter parenting is a qualitatively distinct approach of parenting. However, after reviewing the literature, it seems as though helicopter parenting falls on a spectrum of parenting and consists of several varying levels of parenting dimensions. Operationalizing helicopter parenting in the terms of varying levels of a combination of parenting dimensions (i.e., high care, high involvement, high control, low autonomy support, etc.) would better connect the measurement of this phenomenon with the conceptual definition that Cline and Fay (1990) originally proposed. 


\section{CHAPTER III \\ THE PROPOSED STUDY}

Helicopter parenting is an important concept to further research as previous literature has shown the impact it can have on college student adjustment and well-being. Helicopter parenting is described as parental involvement taken to a dysfunctional level and is used synonymously with the term, over-parenting, in recent publications (BradleyGiest \& Olson-Buchanan, 2014; LeMoyne \& Buchanan, 2011; Segrin et al., 2013). Research has shown that helicopter parenting is distinct from other parenting behaviors such as, behavioral control, psychological control, and involvement (Bradley-Giest \& Olson Buchanan, 2014; Padilla-Walker \& Nelson, 2012). More research is needed to more clearly define helicopter parenting as many studies do not use the same measure in regards to operationalizing the concept of helicopter parenting.

The purpose of this study was to find a way to measure helicopter parenting that directly reflects its conceptual definition that has been established by Cline and Fay (1990). Literature has pointed to several parenting dimensions that constitute helicopter parenting (Kins \& Soenens, 2013; Klein \& Pierce, 2009). Rather than looking at helicopter parenting as a qualitatively distinct approach to parenting, this study attempted to show that parenting dimensions established in existing literature are what constitutes helicopter parenting. Helicopter parenting should be looked at as falling on an extreme end of the spectrum of different parenting dimensions. 
This study attempted to show that a combination of higher levels of parental overprotection, care, psychological control, behavioral control, involvement, moderate levels of responsiveness, and lower levels autonomy support will provide a comprehensive picture of what helicopter parenting truly consists of (Kins \& Soenens, 2013; Klein \& Pierce, 2009; Padilla-Walker \& Nelson, 2012).

\section{Exploratory Analyses}

The primary focus of this study was to find a more efficient and comprehensive way of measuring helicopter parenting. Exploratory analyses were done to evaluate whether a combination of varying levels of parenting dimensions constitute helicopter parenting. Along with exploratory analysis, a comparison was made between measuring helicopter parenting as a combination of varying levels of parenting dimensions and Odenweller and colleagues' (2014) HPI. It was hypothesized that the parenting dimensions used to constitute helicopter parenting would all be correlated with the HPI that Odenweller and colleagues (2014) used in their study. More specifically I hypothesized:

\section{Hypothesis 1}

There would be a positive association between parental care and Odenweller and colleagues' (2014) HPI. Research has not directly looked at the association between parental care and helicopter parenting. However, the definition of helicopter parenting may imply that parental care is in fact a dimension. Items found on the PBI measuring parental care reveal a potential relationship with helicopter parenting; reporting that a parent Did not help me as much as I needed and Did not talk with me very much, would indicate a lower score on the parental care subscale of the PBI (Parker et al., 1979). 
Because research has shown how helicopter parenting reflects parents who are heavily involved in their child's life, it is appropriate to hypothesize that helicopter parenting would be positively associated with parental care (Bradley-Giest \& Olson-Buchanan, 2014; Schiffrin et al., 2012).

\section{Hypothesis 2}

There would be a positive association between parental overprotection and Odenweller and colleagues' (2014) HPI. Multiple studies have looked at parental overprotection as a leading dimension behind helicopter parenting (Kins \& Soenens, 2013; Klein \& Pierce, 2009). Additionally, according to the original definition by Cline and Fay (1990) helicopter parents are trying to prevent their child from any possible failures, thus showing protective characteristics. Though research has not looked directly at the relationship between overprotection and helicopter parenting, previous literature points to the salience of overprotection as a dimension of helicopter parenting.

\section{Hypothesis 3}

There would be a positive association between parental psychological control and Odenweller and colleagues' (2014) HPI. Parental psychological control has been found to be associated with helicopter parenting in Padilla-Walker and Nelson's (2012) study. Odenweller and colleagues (2014) developed their measure of helicopter parenting by looking through previous research on this topic; Padilla-Walker and Nelson's (2012) study was one of the studies that was examined. Since, Odenweller and colleagues (2014) referenced Padilla-Walker and Nelson (2012) during their process of developing the measure of helicopter parenting and because these measures claim to be measuring the same phenomenon, it is hypothesized that the same results will occur in the current study. 


\section{Hypothesis 4}

There would be a positive association between parental behavioral control and Odenweller and colleagues' (2014) HPI. Padilla-Walker and Nelson (2012) found that behavioral control was associated with their measure of helicopter parenting. Odenweller and colleagues (2014) developed their measure of helicopter parenting partly by looking at Padilla-Walker and Nelson's (2012) study and since both measures are claiming to assess helicopter parenting, it was predicted that this study would reflect the same results.

\section{Hypothesis 5}

There would be a positive association between parental responsiveness and Odenweller and colleagues' (2014) HPI. There is no current literature that has directly examined the association between responsiveness and helicopter parenting. However, the responsiveness scale contains items that reflect the kind of parental involvement (i.e., $M y$ mother/father gives me a lot of care and attention) associated with the definition of helicopter parenting (Soenens, et al., 2004).

\section{Hypothesis 6}

There would be a positive association between parental involvement and Odenweller and colleagues' (2014) HPI. Many of the studies focusing on helicopter parenting look at parental involvement as an important dimension of helicopter parenting and is taken into consideration when developing measures of helicopter parenting (LeMoyne \& Buchanan, 2011; Odenweller et al., 2014; Padilla-Walker \& Nelson, 2012; Segrin et al., 2012). Padilla-Walker and Nelson (2012) also found that parental involvement was positively associated with their helicopter parenting measure. Because previous literature has pointed to helicopter parenting as parents who are highly involved 
in their child's life, it was hypothesized that there would be a strong positive association between parental involvement and helicopter parenting.

\section{Hypothesis 7}

There would be a negative association between parental autonomy support and Odenweller and colleagues' (2014) HPI. Padilla-Walker and Nelson (2012) found that parental autonomy support was negatively associated with their helicopter parenting instrument. Klein and Pierce (2009) discussed that overprotective parents may hinder autonomy development in their offspring leading to more college adjustment problems. Schiffrin and colleagues (2014) also found a negative association between their measure of helicopter parenting and autonomy.

\section{Helicopter Parenting and Outcome Measures}

While the primary focus of this study aimed to find a more comprehensive way of measuring helicopter parenting, there were also specific hypotheses regarding the relationship between reports of helicopter parenting and various outcome variables.

\section{Hypothesis 8}

Odenweller and colleagues (2014) found that helicopter parenting was associated with interpersonal dependency. For the current study, it was hypothesized that the combination of varying levels of parenting dimensions (higher levels of parental overprotection, care, psychological control, behavioral control, responsiveness, invasiveness and lower levels autonomy support) would be predictive of higher levels of interpersonal dependency. 


\section{Hypothesis 9}

Odenweller and colleagues (2014) found that helicopter parenting was associated with poor coping efficacy. For the current study, it was hypothesized that the combination of varying levels of parenting dimensions (higher levels of parental overprotection, care, psychological control, behavioral control, responsiveness, invasiveness and lower levels autonomy support) would be predictive of lower levels of coping efficacy.

\section{Hypothesis 10}

The combination of varying levels of parenting dimensions (higher levels of parental overprotection, care, psychological control, behavioral control, responsiveness, invasiveness and lower levels autonomy support) would be predictive of lower levels of psychological well-being. 


\section{CHAPTER IV}

\section{METHODS}

\section{Participants}

There were a total of 500 participants that consented to participate in this study. One hundred and forty-eight cases were deleted due to lack of responses to the items that were presented; this resulted in a total of 352 participants whose data were included in the analyses. The final sample was primarily Caucasian (77.8\%) and Female (85.8\%). Other ethnicities included 11.9\% African Americans, 2.6\% Asian, and 7.4\% Latino(a)/Hispanic. The average age was $20.6(S D=3.15), 93.9 \%$ reported that they were college freshman-seniors (others reported being a graduate student, student at large, dually enrolled in high school and fifth year senior) and $79.2 \%$ reported that they were not living at home with their parents.

\section{Measures}

\section{Demographics}

A demographic survey assessed the participants' age, race/ethnicity, gender, year in college, and living situation (living with caregivers versus living without caregivers).

\section{Helicopter Parenting}

To compare the proposed measure of helicopter parenting to a current way of measuring helicopter parenting, the HPI developed by Odenweller and colleagues (2014) was used. Odenweller and colleagues (2014) created their measure of helicopter 
parenting based on the most up-to-date literature available (Padilla-Walker \& Nelson, 2012; Segrin et al., 2012). The HPI was comprised of 15 items assessing the adolescents' perceived helicopter parenting experiences; my parent tries to make all of my major decisions, is an example of one of the items found on this measure (Odenweller et al., 2014). Participants indicated whether they very strongly disagree (1) to very strongly agree (7) with each statement in regards to the HPI. Reliability of the HPI has been reported at .78 .

Parental Psychological Control, Behavioral Control, Responsiveness, and Autonomy Support

The Louvain Adolescent Perceived Parenting Scale was used to assess these four parenting dimensions (LAPPS; Soenens, et al., 2004). The LAPPS is comprised of four subscales measuring psychological control, behavioral control, responsiveness, and autonomy support. The subscales regarding responsiveness ( 7 items; i.e., $M y$ father/mother gives me a lot of care and attention), behavioral control (7 items; i.e., My father/mother insists that I must do exactly as I am told), and psychological control (7 items; i.e., My father/mother is always trying to change me) were created by taking items from the Child Report of Parental Behavior Inventory (CRPBI; Schludermann \& Schludermann, 1988). The psychological control scale also included some items from the Parenting Scales (PS; Lamborn, et al., 1991). The autonomy support subscale (7 items; i.e., My father/mother encourages me to be independent from him) was created by taking items from the Perception of Parents Scale (POPS; Grolnick, et al., 1997). Each item was scored from 1, not at all true, to 5, very much true (Soenens et al., 2004). Reliabilities of these subscales are found to range from .70 to .91 when using a sample of emerging 
adults from the ages of 18 to 22 (Soenens et al., 2004; Delhaye, Beyers, Klimstra, Linkowski, \& Goossens, 2012).

\section{Parental Involvement}

In the context of this study, parental involvement was described as parent's involvement in their offspring's life to promote academic and social success. Because parental involvement is considered to be multidimensional, other parenting dimensions (i.e., control, protection, care) may overlap with a general measure of parental involvement. To look at parental involvement that reflects the kind of dysfunctional involvement described as a component of helicopter parenting, the Parental Invasive Behavior Instrument was used (Ledbetter \& Vik, 2012). Odenweller and colleagues (2014) suggested the use of this measure to develop the dysfunctional profile of helicopter parents. The Parental Invasive Behavior Instrument consisted of 11 items; five items looked at mediated invasion (i.e., my parents look through my call list on my cell phone without my permission), three items looked at verbal invasion (i.e., my parents demand that I change my behavior in some area of my life), and three items looked at spatial invasion (i.e., my parents go through my personal belongings without my permission; Ledbetter \& Vik, 2012). Reliabilities of these items demonstrated acceptable internal reliabilities ranging from .74 to .79 (Ledbetter \& Vik, 2012).

\section{Parental Care and Overprotection}

To measure the level of parental care and over-protection, the Parental Bonding Instrument by Parker and colleagues (1979) was utilized. This scale has been shown to continue to be a valid measure of perceived parental care and over-protection (Wilhelm, Niven, Parker, \& Hadzi-Pavlovic, 2005). This scale was composed of 25 items that assess 
the amount of care and over-protection the child has received in the first 16 years of their life. Helicopter parenting may imply that parents continue this level of care and overprotection past the first 16 years of their offspring's life, so this measure was adjusted to evaluate how the offspring felt about these parenting characteristics up-todate. Responses followed a 4-point likert scale from Very like to Very unlike. The subscale assessing parental care was composed of 12 items looking at the perceived degree of affection; Was affectionate to me is an example of one of the items found on this subscale (Parker et al., 1979). The subscale assessing parental over-protection was composed of 13 items looking at the perceived constraint, smothering, and overinvolvement of the parent; Tried to control everything I did is an example of one of the items found on this subscale (Parker et al., 1979). During the development of the online survey, one item was accidentally left out of the parental overprotection subscale. Thus, participants were exposed to only 24 items from the PBI, 12 care items and 12 overprotection items.

\section{Coping Efficacy}

An outcome measure assessing coping efficacy was used to compare the two ways of measuring helicopter parenting. Odenweller and colleagues (2014) utilized Bonanno and colleagues (2002) measure of coping efficacy. This four-item measure assessed an individuals' acknowledgement of their own coping abilities. I often feel helpless and want someone else to solve my problems, is an example of one of the items found on this measure. 


\section{Interpersonal Dependency}

An outcome measure assessing interpersonal dependency was used as Odenweller and colleagues (2014) found an association between this and the way they measured helicopter parenting. The Emotional Reliance on Another Person subscale from the Interpersonal Dependency scale (Hirschfield et al., 1977) was used as this was the measure that Odenweller and colleagues (2014) utilized. The Emotional Reliance on Another Person subscale is comprised of 17 items assess and individuals' emotional attachment and dependency on another person; I need to have one person who puts me above all others, is an example of one of the items that can be found on this subscale (Hirschfield et al., 1977). The reliability of this subscale has been found at .85 (Odenweller et al., 2014).

\section{Psychological Well-Being}

The current study also measured psychological well-being using the Flourishing Scale developed by Diener and colleagues (2010). The scale consisted of eight items assessing aspects of human functioning as described originally by Ryff (1989). The scale was originally called Psychological Well-being (Diener et al., 2009); however the scale grasps a more broad definition of psychological well-being so the name was changed to more accurately reflect what is being measured. Participants were asked to answer each item on a scale of one (strong disagreement) to seven (strong agreement). Scores can range from eight to 56; high scores indicated positive psychological well-being. Diener and colleagues (2010) found that the Flourishing scale provides a good assessment of overall psychological well-being with internal reliability reported at .87 and temporal stability found at .71. 


\section{Procedure}

Participants were directed to a link of the survey via a recruitment email by the Research Listserv or through the SONA Systems available to use through ISU. Upon clicking the survey link, participants were shown a documentation of informed consent where continuing onto the next page of the survey would indicate that consent to participate in the study had been given. Continuing with the survey participants were given the demographics survey as well as the measures involved with assessing helicopter parenting and the various outcome measures. The parenting dimensions were presented to the participants first to prevent incompletion of the measures this study focused on. Following the parenting dimensions participants were then asked to complete the outcome measures and the demographic questions were shown last. 


\section{CHAPTER V}

\section{RESULTS}

\section{Exploratory Factor Analysis}

An exploratory factor analysis was performed to look at the 63 items proposed to measure the phenomenon of helicopter parenting. A number of criteria were checked before examining the factors and factor loadings of the analysis. A correlation analysis revealed that all items were significantly correlated with at least one other item. The results of the Kaiser-Meyer-Olkin (KMO) measure of sampling adequacy and Bartlett's test of sphericity were also examined. A KMO of .93 and a significant sphericity test, $\chi^{2}(1953)=17078.42, p<.001$, further indicated that a factor analysis could be performed efficiently.

A principle axis factor analysis was performed to find the least number of factors among the examined items. Initial eigenvalues revealed that the first through seventh factors explained $28.1 \%, 10.9 \%, 7.1 \%, 5.7 \%, 4.9 \%, 3.6 \%$, and $3.2 \%$ of the variance, respectively. The eighth through $11^{\text {th }}$ factors that had eigenvalues just over one explained $2.6 \%, 2.4 \%, 1.8 \%$, and $1.6 \%$ of the variance, respectively. The eight factor solution, which explained $66 \%$ of the variance, was the preferred solution after closely examining the scree plot and simple structure of factor loadings. A promax (oblique) rotation was utilized to account for multicollinearity among the items. A total of 13 items were eliminated because they did not reveal simple structure and did not meet the loading 
criteria of having a primary loading of .5 with secondary loadings below .3. Item 20 on the Parental Bonding Instrument had a primary factor loading of .61 and a cross-loading of .37; this item was retained due to the low cross-loading and the nature of the item in relation to helicopter parenting (Felt I could not look after myself unless he/she was around).

A principal axis factor analysis was performed on the remaining 50 items using promax rotation revealing eight factors explaining $69.6 \%$ of the variance. All items in this analysis had primary loadings above .5 and all cross-loadings were below .3 , with the exception of item 13 and 24 from the PBI that had a cross-loading of .303 and a primary loading of .492 , respectively. After evaluating the primary and cross-loadings of the two items as well as the content of each, these items were retained. The factor loading matrix for this final solution is presented in Table 1. 
Table 1

Factor Loadings and Communalities Based on a Principle Axis Factor Analysis with

Promax Rotation for 49 Items from the Survey $(N=352)$

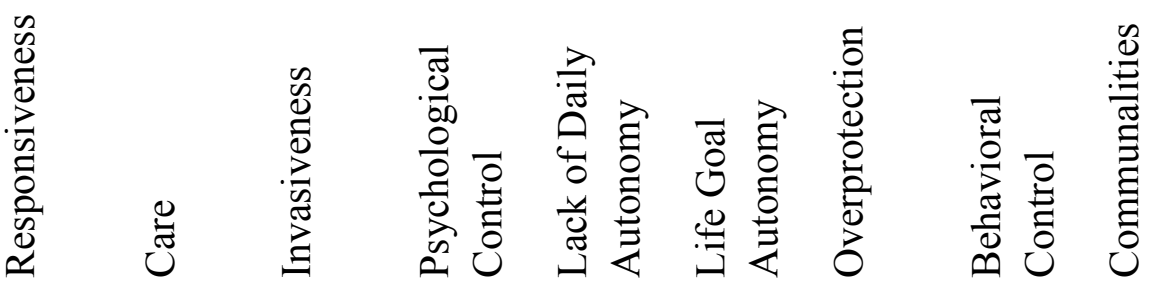

R5 cheers me up when

I am sad.

.99

.89

$\mathrm{R} 3$ is able to make me

feel better when I am

upset.

.98

R1 makes me feel

better after talking over

my worries with

him/her.

.92

.80

R2 smiles at me very

often.

R6 gives me a lot of care and attention.

R7 believes in showing his love for me.

R4 enjoys doing things with me.

PBI1 Spoke to me in a warm and friendly

voice.

PBI12 Frequently smiled at me.

PBI6 Was affectionate to me. 


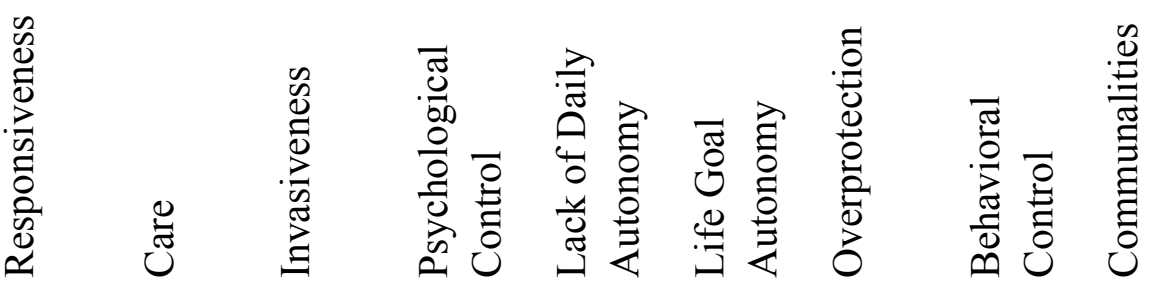

PBI3 Let me do those things I liked doing. $-.80$

PBI11 Enjoyed talking things over with me.

PBI5 Appeared to understand my problems and worries. $\quad-.25 \quad .60$

PBI7 Liked me to make my own decisions.

PBI15 Let me decide things for myself.

PBI24 Did not praise

me

I3 My parents read my private online communication (such as e-mails or IM conversations) without my permission.

I2 My parents read through my text messages without my permission.

I1 My parents look through my call list on my cell phone without my permission. 


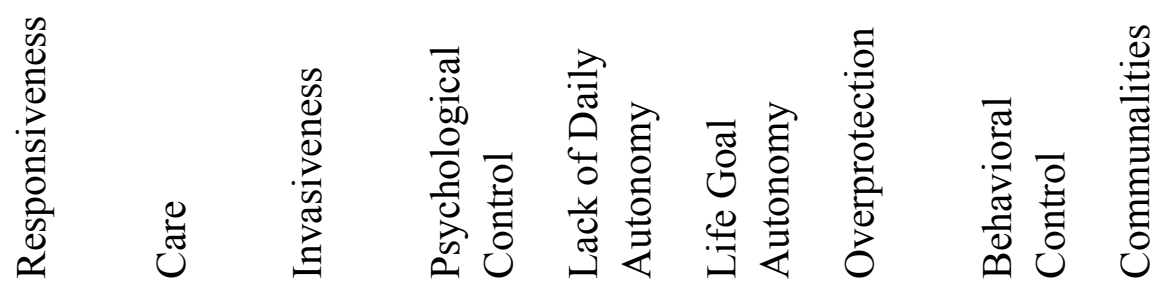

I9 My parents go

through my personal

belongings without my

permission.

I1 1 My parents

eavesdrop on my face-

to-face conversations

with others.

I4 My parents monitor my phone calls by looking over the phone bill.

I10 My parents go

through my postal mail without my

permission.

I5 My parents check up on me through social networking websites such as Facebook or MySpace.

I7 My parents ask personal questions that I dont want to answer.

PC4 if I have hurt his feelings, stops talking to me until I please him/her again. 


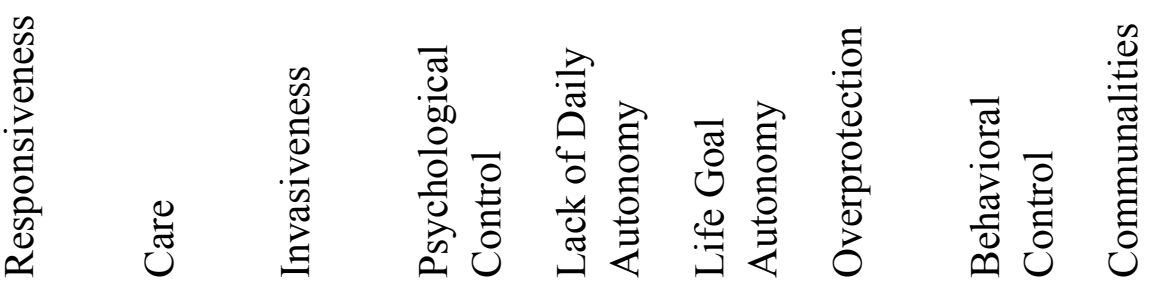

PC5 won't let me do things with him/her, when I do something he doesn't like.

PC7 acts cold and unfriendly if I do something he/she doesn't like.

PC3 will avoid looking at me when I have disappointed him/her.

PC2 is less friendly

with me, if I do not see things his/her way.

$\mathrm{PC} 1$ is always trying to change me.

PC6 make my life miserable when I get a poor grade at school.

BC6 lets me go out any evening I want.

BC5 lets me go any place I please without asking.

BC7 lets me do anything I like to do.

$\mathrm{BC} 4$ gives me as much freedom as I want. 


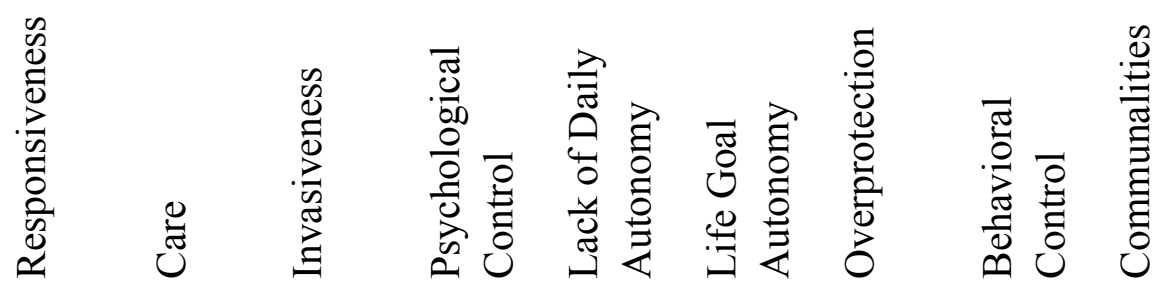

AS4 whenever

possible, allows me to choose what to do.

AS5 allows me to decide things for myself.

AS3 encourages me to be independent from him/her.

AS2 often tells me that I must think about my life myself.

AS1 lets me make my own plans for things I want to do.

PBI20 Felt I could not look after myself unless he/she was around.

PBI10 Invaded my privacy.

PBI9 Tried to control everything I did.

PBI23 Was

overprotective of me.

PBI13 Tended to baby me. 


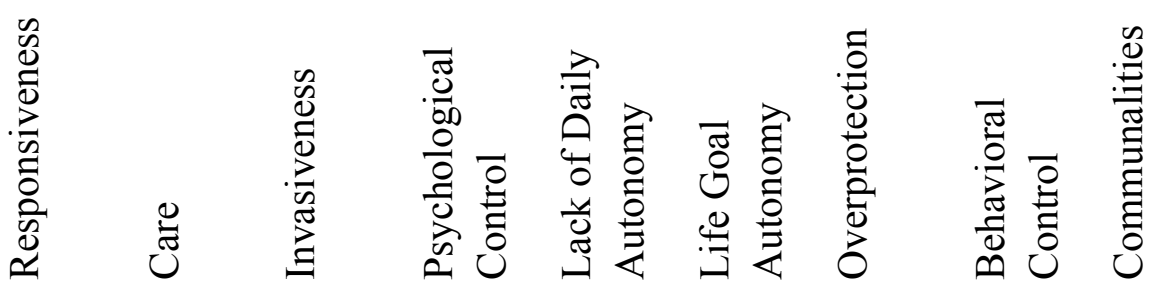

PBI19 Tried to make

me feel dependent on

him/her.

.64

$\mathrm{BC} 2$ insists that I must

do exactly as I am told.

$\mathrm{BC} 1$ believes in having

a lot of rules and

sticking with them.

$\mathrm{BC} 3$ is very strict with

me.

Note. Factor loadings $<.20$ are suppressed. Items are labeled according to the scale they originated from $(\mathrm{R}=\mathrm{Responsiveness}$ subscale of the LAPPS, $\mathrm{PBI}=$ Parental bonding instrument [Care and Overprotection subscales], I=Invasiveness, $\mathrm{PC}=$ Psychological Control subscale of the LAPPS, AS=Autonomy Support subscale of the LAPPS, $\mathrm{BC}=$ Behavioral Control subscale of the LAPPS). 
The goal of this factor analysis was to come up with a multidimensional approach to measuring helicopter parenting while also keeping in mind the extent of its length. To keep the number of items consistent across factors, each factor was reduced to having a range of 3-6 items. Items were carefully chosen based on content (similarity between items and relevance to helicopter parenting) and loading value. The factor labels applied in this study coincided with the original scale the items loaded on (Care, Responsiveness, Invasiveness, Psychological Control, Overprotection, and Behavioral Control). Two factor labels (Lack of Daily Autonomy and Life Goal Autonomy) were differentially named due to the content of items loading on these two factors. All items from the autonomy support subscale of the LAPPS loaded on the Life Goal Autonomy factor. There were four items that came from the behavioral control subscale of the LAPPS that were reverse coded (i.e., gives me as much freedom as I want), these items were labeled as Lack of Daily Autonomy and higher scores indicate the absence of daily autonomy support.

After finalizing the items in each factor, internal consistency for each of the factors was determined using Cronbach's alpha. Alphas revealed all items in each factor had relatively high internal consistency: .90 for Care ( 6 items), .95 for Responsiveness (6 items), .83 for Invasiveness (6 items), .92 for Psychological Control (6 items), .93 for Lack of Daily Autonomy Support (4 items), .82 for Overprotection (6 items), .86 for Life Goal Autonomy Support (5 items), and .89 for Behavioral Control (3 items).

Composite scores were created for each of the eight factors. Higher scores indicated that a child reported their parents having more of the attribute. Skewness of each factor ranged between -.72 to 1.56 and kurtosis ranged from -.73 to 2.63 , an 
examination of each factor's density plot further indicated that the distributions were approximately normal. An oblique rotation was used to account for correlations among the data, the results of the correlation analysis between each factor are presented in Table 2.

The final 42-item survey revealed eight factors that reflected participants' reports of their parents' behaviors that may constitute helicopter parenting. Overall, the factors revealed in this measure were highly internally consistent and composite scores indicated an approximately normal distribution. High scores on every factor with the exception of the Life Goal Autonomy factor are proposed to be indicative of the helicopter parenting phenomenon.

\section{Bivariate Correlation Analyses}

To assess hypotheses one through seven, bivariate correlations were performed looking at each parenting dimension and its association with the HPI. Hypothesis one predicted that there would be a positive association between parental care and the HPI. Analyses were conducted using the composite Care factor. Results revealed that there was a positive association found between reports of parental care and the HPI, $r(343)=$ $.14, p=.01$. Hypothesis two predicted that there would be a positive association between parental overprotection and the HPI. Analyses were conducted using the composite Overprotection factor. Results revealed that there was a significant negative association between parental overprotection and the HPI, $r(343)=-.30, p<.001$. Hypothesis three predicted that there would be a positive association between psychological control and the HPI. Analyses were conducted using the composite Psychological Control factor. 
Results revealed that there was a significant association found between psychological control and the HPI, $r(343)=.42, p<.001$.

Hypothesis four predicted that there would be a positive association between behavioral control and the HPI. Analyses were conducted using the Behavioral Control factor. Results revealed that there was a significant positive correlation between behavioral control and the HPI, $r(343)=.30, p<.001$. Hypothesis five predicted that there would be a positive association between responsiveness and the HPI. Analyses were conducted using the Responsiveness factor. Results revealed that there was no significant association between responsiveness and the HPI, $r(343)=-.03, p=.56$. Hypothesis six predicted that there would be a positive association between parental involvement and the HPI. Analyses were conducted using the Invasiveness factor. Results revealed that there was a significant, positive association between Invasiveness and the HPI, $r(343)=.48, p$ $<.001$. Hypothesis seven predicted that there would be a negative association between autonomy support and the HPI. Analyses were conducting using the Life Goal Autonomy and Lack of Daily Autonomy factors. Life Goal Autonomy was expected to be negatively associated with the HPI due to higher scores indicating more parental autonomy supportive behaviors. Lack of Daily Autonomy was expected to be positively associated with the HPI due to higher scores indicating a lack of parental autonomy supportive behaviors. Results revealed that life goal autonomy and daily autonomy were significantly associated with the HPI in their predicted directions, $r(343)=-.29, p=.00$ and $r(343)=.22, p<.001$, respectively. 
Table 2

Bivariate Correlations Between the Eight Helicopter Parenting Factors $(N=352)$

\begin{tabular}{|c|c|c|c|c|c|c|c|}
\hline & 1 & 2 & 3 & 4 & 5 & 6 & 7 \\
\hline 1.Responsiveness & & & & & & & \\
\hline 2.Psychological & $-0.34 * *$ & & & & & & \\
\hline Control & & & & & & & \\
\hline 3.Care & $-0.65 * *$ & $0.41 * *$ & & & & & \\
\hline 4.Invasiveness & $-0.15 * *$ & $0.35 * *$ & $0.21 * *$ & & & & \\
\hline 5.Lack of Daily & $-0.12 *$ & $0.16 * *$ & 0.08 & $0.20 * *$ & & & \\
\hline Autonomy & & & & & & & \\
\hline 6.Overprotection & $0.24 * *$ & $-0.36 * *$ & $0.39 * *$ & $-0.25 * *$ & $-0.25 * *$ & & \\
\hline 7.Life Goal & $0.32 * *$ & $-0.23 * *$ & $-0.32 * *$ & $-0.16 * *$ & $-0.46 * *$ & $0.32 * *$ & \\
\hline Autonomy & & & & & & & \\
\hline $\begin{array}{l}\text { 8.Behavioral } \\
\text { Control }\end{array}$ & 0.07 & $0.34 * *$ & 0.06 & $0.28 * *$ & $0.29 * *$ & $-0.31 * *$ & -0.05 \\
\hline
\end{tabular}




\section{Multiple Regression}

Hypothesis eight predicted that there would be an association between the proposed factors of helicopter parenting and interpersonal dependency (as found by Odenweller et. al., 2014). A multiple linear regression was calculated to predict levels of participant reported interpersonal dependency based on reports of the eight parenting factors (Care, Overprotection, Psychological Control, Behavioral Control, Invasiveness, Lack of Daily Autonomy, Responsiveness, and Life Goal Autonomy). Descriptive statistics for this analysis are shown in Table 3. After controlling for the demographic variables, a significant regression equation was found, $R^{2}=.12, F(16,313)=2.65, p=$ .001 , indicating that the significant parenting variables predicted over and above the demographic variables. Of the eight parenting factors, it was found that the Care, Psychological Control, and Overprotection scales significantly predicted reports of interpersonal dependency (see Table 4). Higher reports of parental care $(\beta=.20)$ and overprotection $(\beta=.14)$ were predictive of higher reports of interpersonal dependency whereas, higher reports of parental psychological control $(\beta=-.18)$ were predictive of lower reports of interpersonal dependency.

Hypothesis nine predicted that there would be an association between the proposed factors of helicopter parenting and coping ability. A multiple linear regression was performed to predict levels of participant reported coping ability based on reports of the eight parenting factors. Descriptive statistics for this analysis is shown in Table 3. After controlling for the demographic variables, a significant regression equation was found, $R^{2}=.10, F(16,311)=2.31, p=.003$, indicating that the significant parenting variables predicted over and above the demographic variables. Specifically, it was found 
that Psychological Control significantly predicted reports of coping ability; higher reports of parental psychological control $(\beta=-.19)$ were predictive of higher reports of coping efficacy (see Table 5).

Hypothesis 10 predicted that there would be an association between the eight helicopter parenting factors and psychological well-being. A multiple linear regression was performed to examine predicted levels of participant reported psychological wellbeing based on reports of the helicopter parenting factors. Descriptive statistics for this analysis is shown in Table 3. After controlling for the demographic variables, a significant regression equation was found, $R^{2}=.16, F(16,313)=3.83, p<.001$, indicating that some of the parenting variables predicted over and above the demographic variables. Specifically, it was found that Psychological Control, Life Goal Autonomy, and Behavioral Control significantly predicted reports of psychological well-being (see Table 6). Higher reports of life goal autonomy $(\beta=.13)$ and behavioral control $(\beta=.16)$ were predictive of higher reports of psychological well-being whereas, higher reports of psychological control $(\beta=-.21)$ was predictive of lower reports of psychological wellbeing. 
Table 3

Descriptive Statistics of the Hierarchical Linear Regression (Parenting Measures and Outcomes Only)

\begin{tabular}{llr}
\hline & $N$ & Mean $(S D)$ \\
\hline Interpersonal Dependency & 339 & $2.24(0.61)$ \\
Coping Efficacy & 337 & $4.25(0.83)$ \\
Psychological Well-Being & 338 & $46.49(8.35)$ \\
Care & 352 & $0.78(0.61)$ \\
Responsiveness & 352 & $3.99(0.86)$ \\
Invasiveness & 344 & $0.95(1.00)$ \\
Psychological Control & 352 & $1.87(0.80)$ \\
Lack of Daily Autonomy & 352 & $2.97(1.03)$ \\
Overprotection & 352 & $1.98(0.58)$ \\
Life Goal Autonomy & 352 & $3.85(0.74)$ \\
Behavioral Control & 352 & $2.88(0.89)$ \\
\hline
\end{tabular}


Table 4

Regression of Demographic (Control) and Parenting (Predictor) Variables Predicting Interpersonal Dependency $(N=329)$

\begin{tabular}{lrrrrrr}
\hline \multirow{1}{*}{ Variable } & \multicolumn{3}{c}{ Model 1 } & \multicolumn{3}{c}{ Model 2 } \\
\cline { 2 - 7 } & $\mathrm{B}$ & $S E(\mathrm{~B})$ & $\beta$ & $\mathrm{B}$ & $S E(\mathrm{~B})$ & $\beta$ \\
\hline African-American & 0.12 & 0.15 & 0.07 & 0.08 & 0.15 & 0.04 \\
Hispanic & 0.31 & 0.16 & $0.13^{*}$ & 0.23 & 0.16 & 0.10 \\
Asian & -0.24 & 0.21 & -0.06 & -0.23 & 0.21 & 0.10 \\
Caucasian & 0.06 & 0.14 & 0.04 & 0.03 & 0.14 & 0.02 \\
Gender & -0.34 & 0.10 & $-0.20^{* *}$ & -0.35 & 0.10 & $-0.20^{* *}$ \\
Age & -0.01 & 0.01 & -0.05 & -0.01 & 0.02 & -0.04 \\
Living Situation & 0.01 & 0.08 & 0.01 & 0.01 & 0.08 & 0.00 \\
Education & 0.07 & 0.04 & $0.15^{*}$ & 0.06 & 0.04 & 0.13 \\
Care & & & & 0.20 & 0.08 & $0.20^{*}$ \\
Responsiveness & & & & 0.02 & 0.05 & 0.02 \\
Invasiveness & & & & 0.00 & 0.04 & 0.01 \\
Psychological Control & & & & -0.14 & 0.05 & $-0.18^{* *}$ \\
Lack of Daily Autonomy & & & & 0.01 & 0.04 & 0.02 \\
Overprotection & & & & 0.14 & 0.07 & $0.14^{*}$ \\
Life Goal Autonomy & & & & -0.01 & 0.06 & -0.01 \\
Behavioral Control & & & & 0.07 & 0.04 & 0.11 \\
$R^{2}$ & & 0.07 & & & 0.12 & \\
$F$ for change in $R^{2}$ & $3.14 * *$ & & & $2.08^{*}$ & \\
\hline
\end{tabular}

$* p<.05 .{ }^{*} p<.01$. 
Table 5

Regression of Demographic (Control) and Parenting (Predictor) Variables Predicting Coping Efficacy $(N=327)$

\begin{tabular}{lrrrrrr}
\hline & \multicolumn{3}{c}{ Model 1 } & \multicolumn{3}{c}{ Model 2 } \\
\cline { 2 - 7 } \multicolumn{1}{c}{ Variable } & $\mathrm{B}$ & $S E(\mathrm{~B})$ & $\beta$ & $\mathrm{B}$ & $S E(\mathrm{~B})$ & $\beta$ \\
\hline African-American & -0.18 & 0.21 & -0.07 & -0.10 & 0.21 & -0.04 \\
Hispanic & -0.50 & 0.22 & $-0.16^{*}$ & -0.43 & 0.22 & -0.13 \\
Asian & 0.38 & 0.29 & 0.08 & 0.40 & 0.29 & 0.08 \\
Caucasian & -0.20 & 0.19 & -0.09 & -0.09 & 0.19 & -0.04 \\
Gender & 0.14 & 0.13 & 0.06 & 0.18 & 0.13 & 0.08 \\
Age & -0.03 & 0.02 & -0.10 & -0.02 & 0.02 & -0.08 \\
Living Situation & 0.06 & 0.11 & 0.03 & 0.03 & 0.11 & 0.01 \\
Education & 0.09 & 0.05 & 0.14 & 0.07 & 0.05 & 0.11 \\
Care & & & & -0.11 & 0.11 & -0.08 \\
Responsiveness & & & & -0.03 & 0.07 & -0.03 \\
Invasiveness & & & & -0.02 & 0.05 & -0.02 \\
Psychological Control & & & & 0.20 & 0.07 & $-0.19 * *$ \\
Lack of Daily Autonomy & & & & -0.01 & 0.05 & -0.02 \\
Overprotection & & & & 0.06 & 0.10 & 0.04 \\
Life Goal Autonomy & & & & 0.14 & 0.08 & 0.12 \\
Behavioral Control & & & & 0.12 & 0.06 & 0.13 \\
$R^{2}$ & & 0.04 & & & 0.11 & \\
$F$ for change in $R^{2}$ & & 1.69 & & & $2.31^{* *}$ \\
\hline
\end{tabular}

$* p<.05 .{ }^{* *} p<.01$. 
Table 6

Regression of Demographic (Control) and Parenting (Predictor) Variables Predicting Psychological Well-Being $(N=329)$

\begin{tabular}{lrrrrrr}
\hline & \multicolumn{3}{c}{ Model 1 } & \multicolumn{3}{c}{ Model 2 } \\
\cline { 2 - 7 } \multicolumn{1}{c}{ Variable } & $\mathrm{B}$ & $S E(\mathrm{~B})$ & \multicolumn{1}{c}{$\beta$} & $\mathrm{B}$ & $S E(\mathrm{~B})$ & $\beta$ \\
\hline African-American & -0.17 & 2.01 & -0.01 & 0.16 & 2.01 & 0.01 \\
Hispanic & 1.08 & 2.22 & 0.03 & 1.16 & 2.14 & 0.04 \\
Asian & -3.50 & 2.96 & -0.07 & -2.21 & 2.84 & -0.04 \\
Caucasian & -0.83 & 1.94 & -0.04 & -0.96 & 1.88 & -0.04 \\
Gender & 2.25 & 1.34 & 0.09 & 1.83 & 1.29 & 0.08 \\
Age & -0.29 & 0.20 & -0.11 & -0.15 & 0.20 & -0.06 \\
Living Situation & 0.94 & 1.15 & 0.05 & 0.03 & 1.10 & 0.00 \\
Education & 1.20 & 0.51 & $0.18^{*}$ & 0.93 & 0.49 & 0.14 \\
Care & & & & -1.41 & 1.04 & -0.10 \\
Responsiveness & & & & 0.19 & 0.72 & 0.02 \\
Invasiveness & & & & 0.24 & 0.49 & 0.03 \\
Psychological Control & & & & -2.26 & 0.67 & $-0.21^{* *}$ \\
Lack of Daily Autonomy & & & & 0.10 & 0.52 & 0.01 \\
Overprotection & & & & 0.95 & 0.92 & 0.07 \\
Life Goal Autonomy & & & & 1.50 & 0.75 & $0.13^{*}$ \\
Behavioral Control & & & & 1.55 & 0.60 & $0.16^{*}$ \\
$R^{2}$ & & 0.04 & & & 0.16 & \\
$F$ for change in $R^{2}$ & & 1.64 & & & $3.83^{* *}$ \\
\hline
\end{tabular}

$* p<.05 .{ }^{* *} p<.01$. 


\section{CHAPTER VI \\ DISCUSSION}

\section{Reliability of Proposed Measure}

Overall, I found evidence for a multidimensional measure of helicopter parenting using eight factors created from previous parenting measures. The theoretically driven factor analysis resulted in a 42-item scale. After creating composite scores of each factor, analyses revealed that the factors had high internal consistency. Thus, the proposed multidimensional measure of helicopter parenting had shown to have strong reliability among the eight subscales. The eight factor model is also further supported, as theory and recent research has pointed to the multidimensionality of this phenomenon.

\section{Validity of Proposed Measure}

Overall, the results of hypotheses one through 10 provided evidence of validity. Specifically, five out of the seven correlational analyses between the factors found in the proposed measure and the HPI were significant. These correlational results indicated that the newly proposed multidimensional measure is, in fact, measuring the phenomenon of helicopter parenting. The significant multiple regressions that were similar to the results found by Odenweller and colleagues' (2014) also further supported the validity of the multidimensional measure. 


\section{Hypothesis 1}

As expected, a significant association between parental care and the Helicopter Parenting Instrument was found. Theory points to the potential importance of parental care as an aspect of helicopter parenting, as it can be implied that parents care about their children who they are protecting from failure (Bradley-Giest \& Olson-Buchanan, 2014; Schiffrin et al., 2012). Prior to this study there has been no research directly examining the relationship between helicopter parenting measures and a measure of care. The positive association between parental care and helicopter parenting sheds light on the lack of information regarding this relationship. This relationship also further supports the development of the multidimensional measure of helicopter parenting. Parents who are identified as helicopter parents do show care for their offspring. It is important that this behavior is considered when conducting research on helicopter parenting, as care is a salient aspect of this phenomenon.

\section{Hypothesis 2}

The hypothesis was not supported by the results, indicating a relationship between parental overprotection and the Helicopter Parenting Instrument in the opposite direction than was predicted. It was revealed that Parental overprotection was related to lower scores on the Helicopter Parenting Instrument. After comparing the items from the overprotection scale to the items found on the Helicopter Parenting Instrument, a few conclusions were made. Items that were retained by the overprotection scale (Tried to control everything I did, Tended to baby me, Was overprotective of me) were very similar to items found in the Helicopter Parenting Instrument (My parent tries to make all of my major decisions, My parent considers oneself a bad parent when he or she does not step 
in and 'save' me from difficulty). The items from the overprotection scale were in past tense as opposed to the items from the Helicopter Parenting Instrument. Though participants were instructed to think about the current relationship with their parents, they could have answered in a more reflective mindset after reading the items that were phrased in past tense. It is also important to note that the Helicopter Parenting Instrument is a one-factor model. There were only a few items (such as those listed above) that reflected parental overprotection. The Parental Bonding Instrument has been shown to contain a reliable and valid measure of parental overprotection, so it may be the case that Odenweller and colleagues' (2014) Helicopter Parenting Instrument may not distinctly measure the overprotective nature of helicopter parents.

\section{Hypothesis 3}

The hypothesis was supported by the results, indicating a positive relationship between parental psychological control and the Helicopter Parenting Instrument. This coincides with the results found by Padillw-Walker and Nelson (2012), who found an association with their helicopter parenting measure and psychological control. This also

further suggests that psychological control may be a facet of helicopter parenting instead of being qualitatively distinct from this phenomenon. It may be the case that helicopter parents exhibit psychological controlling behaviors to ensure involvement in their children's decision-making. It is evident that parents who are identified as helicopter parents often-times want to be completely involved in any decisions their children may make such as, educational degree and occupation (LeMoyne \& Buchanan, 2011; PadillaWalker \& Nelson, 2012). 


\section{Hypothesis 4}

The hypothesis was supported by the results indicating that there was a positive relationship between behavioral control and the Helicopter Parenting Instrument. This further supports the results found by Padilla-Walker and Nelson (2012) who found similar results with their measure of helicopter parenting and behavioral control. This result also suggests that behavioral control (like psychological control) may be a facet of helicopter parenting instead of qualitatively distinct as proposed by Padilla-Walker and Nelson (2012). Helicopter parents may exhibit behavioral control for various reasons such as, protecting them from certain harm they may encounter or preventing them from failing at any task presented. Parenting dimensions such as behavioral control allow a helicopter parent to maximize the amount of hovering they are able to do over their children. Theory also points to the idea that overall parental control is a salient aspect of helicopter parenting, as controlling behaviors (behavioral and psychological) may hinder autonomy development of the offspring (Chickering \& Reisser, 1990).

\section{Hypothesis 5}

The hypothesis was not supported by the results indicating that there was no relationship found between parental responsiveness and the Helicopter Parenting Instrument. When considering the lack of relationship between this parenting dimension and the Helicopter parenting instrument, it should be noted that Odenweller and colleagues (2014) created a one-factor construct to measure helicopter parenting. The lack of relationship between these two variables does not reflect a lack of responsiveness behaviors among helicopter parents; it is an indication that the Helicopter Parenting Instrument did not take into account that helicopter parents may exhibit responsiveness 
behaviors. Theoretically, helicopter parenting points to heightened parental responsiveness, as they are ready to save their child whenever possible (Cline \& Fay, 2006). Responsiveness is very similar to care in that the parent is attentive to the child's feelings and well-being (i.e., cheers me up when I am sad, gives me a lot of care and attention). The responsiveness items, as opposed to care, focused on how the parent was aware of the child's current emotional state and aimed to make the child feel better and cared for. This is reflective of helicopter parenting behavior and implies that responsiveness may be a salient facet of this phenomenon regardless of the lack of association it has with the Helicopter Parenting Instrument.

\section{Hypothesis 6}

The hypothesis was supported by the results indicating that there was a positive relationship between parental invasiveness and the Helicopter Parenting Instrument. There has been a wide variety of support for the notion that helicopter parents are highly involved in their children's lives to the point that they may be invasive (LeMoyne \& Buchanan, 2011; Odenweller et al., 2014; Padilla-Walker \& Nelson, 2012; Segrin et al., 2012). Padilla-Walker and Nelson (2012) also found that parental involvement was associated with their measure of helicopter parenting. The invasiveness scale was used to look into a negative perspective of parental involvement that is often associated with helicopter parenting. Involvement is theorized as a multidimensional construct such that other dimensions such as parental care, psychological control, behavioral control, responsiveness, and overprotection are indicators that the parent is actually involved in the child's life. However, it is important to consider a more extreme form of involvement when measuring helicopter parenting. Theory has suggested that helicopter parents are 
overly involved parents who are doing too much for their children (Cline \& Fay, 2006). It is important to make sure that the helicopter parents who fall more on an extreme end of the spectrum are accounted for as they could display involvement behaviors that go above and beyond what is being measured by current helicopter parenting surveys such as the Helicopter Parenting Instrument.

\section{Hypothesis 7}

The hypothesis was supported by the results indicating that there was a negative relationship between autonomy support and the Helicopter Parenting Instrument. This finding supports previous research that has suggested or found a negative relationship between autonomy support and the Helicopter Parenting Instrument (Klein \& Pierce, 2009; Padilla-Walker \& Nelson, 2012; Schiffrin et. al., 2014). This relationship indicates the possibility that a lack of autonomy supportive behaviors is characteristic of helicopter parenting. Helicopter parents are theorized as being so involved in their offsprings' lives that they are sometimes still doing laundry, homework, and filling out job applications for them. Instead of giving them the tools to be able to do tasks like the aforementioned, helicopter parents are taking the responsibility into their own hands. When measuring helicopter parenting, it is important to account for this lack of autonomy supportive behavior.

\section{Hypothesis 8}

In an effort to further validate the measure, I used Odenweller and colleagues' (2014) finding of a correlation between their Helicopter Parenting Instrument and interpersonal dependency to examine if the proposed measure found similar relationships. I hypothesized that the eight parenting factors would significantly predict interpersonal 
dependency and this was supported. Three of the eight parenting factors significantly predicted interpersonal dependency (overprotection, psychological control, and care). It was expected that higher reports of all behaviors (except life goal autonomy) would be associated with higher reports of interpersonal dependency. It was found that higher reports of overprotection and care were predictive of higher reports of interpersonal dependency, however, higher reports of psychological control were predictive of lower reports of interpersonal dependency. Offspring that experience parental psychological control may pursue independence more often simply because they are tired of having their decisions, feelings, and emotions controlled by their parents. Those who move away to college (and away from their parents) may report being less interpersonally dependent due to the nature of their surroundings. Though helicopter parents may still exhibit psychologically controlling behaviors while their offspring is away at college, it may be more difficult to retain that offspring dependency when they are not of close proximity to each other. This finding was particularly interesting as it sheds light on the possibility that not all behaviors associated with helicopter parenting lead to the same outcomes. This also suggests the possibility that certain dimensions of helicopter parenting may be predictive of particular outcomes. The relationship between interpersonal dependency and the three significant predictors was positive, indicating that the more a helicopter parent exhibits these behaviors, the more dependent the offspring may become.

\section{Hypothesis 9}

This study found that observed helicopter parenting behaviors are able to predict reports of coping efficacy among adult-offspring. However, the specific results were not as expected. The data indicated that the more psychological controlling behaviors a 
parent exhibited, the better coping ability would be reported of the offspring. This is not consistent with previous research as, Segrin and colleagues (2013) found that their measure of overparenting was associated with poor coping skills, which in turn was associated with reports of anxiety and stress. The mixed results may be due to measurement differences between Segrin and colleagues' (2013) measure of overparenting and the current measure proposed in this study. Reflecting on the nature of helicopter parenting, it may be seen that offspring of helicopter parents who exhibit psychological controlling behaviors report better coping efficacy due to their parents always fixing their problems for them. Offspring of helicopter parents may not experience adverse events due to their parents preventing those kinds of situations at all costs. If an offspring of a helicopter parent does experience adversity, it is not their responsibility to fix the problem so they do not experience the same kind of stress that they may have had if their parents were not helicopter parents. It also could be inferred that offspring who do experience parental psychological control may run into issues of coping efficacy during later adulthood in the absence of their helicopter parent(s).

Bradley-Giest and Olson-Buchanan (2014) found that those who experienced overparenting were indirectly associated with having maladaptive workplace responses. This further supports the possibility that an absence of the helicopter parent may lead to poor outcomes in regards to coping and other self-efficacy characteristics that would normally be reported at higher levels.

\section{Hypothesis 10}

Finally, hypothesis 10 was supported by the results, indicating that three of the 8 parenting factors significantly predicted psychological well-being (psychological control, 
life goal autonomy, and behavioral control). Specifically, the data indicated that the more the psychologically controlling behaviors parents exhibited predicted lower reports of psychological well-being. Whereas, the more autonomy supportive and behavioral controlling behaviors parents exhibited predicted higher reports of psychological wellbeing. Reflecting on past theory and research, these results were expected in regards to the psychological control and life goal autonomy factors. However, it was not expected that behavioral control would be predictive of higher reported psychological well-being. This study explored the association between helicopter parenting and psychological wellbeing due to past research indicating that helicopter parents exhibit these behaviors because they are concerned for their offspring's well-being (Cline \& Fay, 2006; PadillaWalker \& Nelson, 2012). It may be the case that parents who exhibit certain helicopter parenting behaviors such as behavioral control may contribute to their offspring's positive psychological well-being. This may be due to the parents' behavioral controlling behaviors preventing their offspring from facing negative or adverse life events that may result in lower reports of psychological well-being. However, it is clear that helicopter parents who exhibit psychological controlling behaviors and a lack of autonomy supportive behaviors do not contribute to the development of higher reports of psychological well-being. Helicopter parents may have good intentions for their children, but the data indicate that the goals these parents have for their offspring may not be reached if they exhibit particular helicopter parenting behaviors.

Overall, I found evidence that the proposed measure is measuring many of the same constructs as the HPI. Differences between the proposed measure and the HPI can be attributed to the more extensive specificity found in the proposed measure as opposed 
to the HPI. This measure is not only a valid measure of helicopter parenting but reliability analyses have revealed that it is a reliable measure of helicopter parenting as well.

\section{Limitations}

\section{Data Collection Error}

Though there was support found for the multidimensional approach of studying helicopter parenting, there were various limitations to the study that may have affected the data. When data collection first started, there were errors in the phrasing of a few the measures presented (LAPPS and PBI). At certain points in the survey, participants were asked questions about their mother with the question referring to the mother as "him" or "he". This problem was fixed after collecting data from 261 participants. Participants 262-500 were not exposed to any typos in the measures. During data collection, there was also an item missing from the Overprotection subscale of the PBI (Let me dress any way I please). This reduced the amount of items measuring parental overprotection from 13 to 12 .

\section{Measurement Analysis Limitations}

The LAPPS and PBI used in this study recommended that the participant answer for both mother and father separately. The Parental Invasive Behavior Scale asked about both mothers and fathers collectively. To preserve the reliability and validity of each measure, the participants filled out each questionnaire according to their recommendations. To conduct the exploratory factor analysis, the reports for mothers and fathers were averaged together for each participant to come up with a general parenting score. Looking at reports of mothers and fathers separately may lead to different conclusions based on the differences between parenting in a dual-parent household. This 
study may be improved by having participants answer the Parental Invasive Behavior Scale for both parents separately, and then conducting an exploratory factor analysis for both parents separately to compare potential differences between reports of mothers and fathers, as they may exhibit different parenting behaviors.

\section{Sample Limitations}

The sample consisted of primarily Caucasian female college students. It would be beneficial to collect a more diverse sample to ensure the reliability and validity of the multidimensional helicopter parenting survey. Results may vary based on gender of the offspring, ethnic/racial background, and other demographics that may have not been taken into consideration such as, students who are in college versus students who are not currently attending school.

\section{Strengths, Implications and Future Directions}

There were many strengths found in this study despite the various limitations that were presented. Though the sample was not generalizable, it was large enough to adequately run all the proposed analyses. Future research may benefit from a more generalizable sample. Collecting samples that contain equal gender, race, age, and other demographics would allow for analyses comparing different populations furthering our knowledge of the many effects of helicopter parenting.

This study looked into the underlying behaviors that constitute helicopter parenting. Specifically, this research aimed to create a measure of helicopter parenting from pre-existing parenting behavior measures that have been shown to both reliable and valid due to the theoretical framework, high internal consistency among items, as well as the similarity of the results found between the proposed way of measuring helicopter 
parenting and previous research. The final items that were retained for the proposed measure were grasping at broad characteristics of parenting behaviors that are often related to or observed in research on helicopter parenting. Currently available measures of helicopter parenting are often found to be domain-specific and not comprehensively grasping the entirety of this phenomenon. The multidimensional and non-domain-specific aspect of the proposed measure is a major strength of this study, as it is important to accurately measure helicopter parenting for future research in this area.

The proposed measure was further supported when analyses showed that each subscale had high internal reliability. This was expected due to the items originally coming from valid and reliable measures. More research should be conducted to fine-tune the measure and validate its use in helicopter parenting studies. Items were answered on different scales; the overall measure should be adjusted to reflect using the same Likert scale for all items. It is also important to note that the LAPPS and PBI asked about each parent separately and the Invasive Parenting Behavior Scale asked about both parents together; this may have affected the results due to average scores across reports of both mother and father. Future research may benefit from converting the Invasive Parenting Behavior Scale to ask about each parent separately; allowing for analyses to be conducted separately on mother and father reported helicopter parenting. This would be able to account for variations among parenting styles between a mother and father in two-parent homes as well as separated homes where the offspring stay in touch with both parents.

Due to the consistency of results found in the study compared to past research conducted on helicopter parenting, it can be concluded that helicopter parenting can be observed through previously theorized parenting behaviors. The grounded, theory-drive 
approach to measuring helicopter parenting suggests that it is not qualitatively distinct from other forms of parenting. This study supports the idea that helicopter parenting should be viewed as falling on an extreme end of the parenting spectrum. Future research should continue to evaluate where helicopter parenting falls on the spectrum compared to other types of parenting such as indulgent, permissive, authoritative, and authoritarian.

It was unexpected to find that higher reports of psychological control was predictive of lower reports of interpersonal dependency and that higher reports of behavioral control was predictive of higher reports of coping efficacy. These unique findings are indicators that not all aspects of helicopter parenting lead to poor outcomes. It may be that particular helicopter parenting behaviors may lead to wanted outcomes among emerging adult offspring. Future research may benefit from further looking into aspects of helicopter parenting that lead to positive developmental outcomes such as psychological well-being and coping efficacy. Future research may also benefit from observing helicopter parenting among special populations such as, college students who have attention-deficit hyperactivity disorder (ADHD). Current research has shown that college students with ADHD have issues with organization and a lack of focus, which leads to negative outcomes such as poor GPA (Norwalk, Norvilitis, \& MacLean, 2009). Parents who exhibit certain helicopter parenting behaviors may benefit those with ADHD by giving them extra help in areas such as focusing on getting schoolwork done and having an organized schedule.

To conclude, the multidimensional measure of helicopter parenting proposed in this study has revealed eight parenting dimensions that helps create a visual representation of this phenomenon. Future studies that wish to observe helicopter 
parenting should consider the use of this measure, due to its theoretical foundation and high internal reliability. Incorporating the multidimensional aspect to measuring this phenomenon will allow future research to uncover the particular underpinnings of helicopter parenting that may lead to negative or positive outcomes among emerging adults. Due to increased popularity of this phenomenon over media in the U.S., it is important that current research does not misinform the general public. Thus, it is important that researchers know how to adequately measure helicopter parenting to prevent misinterpretations of their results. The current study has successfully attempted to create a measure that provides a comprehensive picture of what helicopter parenting truly consists of. 


\section{REFERENCES}

Alkharusi, H., Aldhafri, S., Kazem, A., Alzubiadi, A., \& Al-Bahrani, M. (2011).

Development and validation of a short version of the Parental Authority Questionnaire. Social Behavior and Personality, 39, 1193-1208.

Anton, W. D., \& Reed, J. R. (1991). College adjustment scales. USA: Psychological Assessment Resources, Inc.

Balistreri, E., \& Busch-Rossnagel, N. A. (1995). Development and preliminary validation of the ego identity process questionnaire. Journal of Adolescence, 18, 179-192.

Bonanno, G. A., Wortman, C. B., Lehman, D. R., Tweed, R. G., Haring, M., Sonnega, J., .. Nesse, R. M. (2002). Resilience to love and chronic grief: A prospective study from preloss to18-months postloss. Journal of Personality and Social Psychology, $83,1150-1164$.

Bradley-Geist, J. C., \& Olson-Buchanan, J. B. (2014). Helicopter parents: An examination of the correlates of over-parenting of college students. Education+ Training, 56(4), 314-328.

Carbery, J., \& Buhrmester, D. (1998). Friendship and need fulfillment during three phases of young adulthood. Journal of Social and Personal Relationships, 15, 393-409.

Chickering, A. W., \& Reisser, L. (1993). Education and Identity. Jossey-Bass Inc: San Francisco. 
Cline, F., Fay, J., \& Cline, F. (2006). Parenting teens with love and logic : preparing adolescents for responsible adulthood / Foster W. Cline and Jim Fay. Colorado Springs, CO : NavPress, c2006.

Cline, F., \& Fay, J. (1990). Parenting with love and logic. Colorado Springs, CO.

Delhaye, M., Beyers, W., Klimstra, T. A., Linkowski, P., \& Goossens, L., (2012). The Leuven Adolescent Perceived Parenting Scale (LAPPS): Reliability and validity with French-speaking adolescents in Belgium. Psychologica Belgica, 52, 289305. doi: $10.5334 / \mathrm{pb}-52-4-289$

DeVellis, R. F. (1991). Scale development: Theory and applications (3rd ed.). Thousand Oaks, CA: Sage.

Diener, E., Wirtz, D., Biswas-Diener, R., Tov, W., Kim-Prieto, C., Choi, D. W., \& Oishi, S. (2009). New measures of well-being (pp. 247-266). Springer Netherlands.

Diener, E., Wirtz, D., Tov, W., Kim-Prieto, C., Choi, D. W., Oishi, S., \& Biswas-Diener, R. (2010). New well-being measures: Short scales to assess flourishing and positive and negative feelings. Social Indicators Research,97(2), 143-156.

Fredericks, J. A., Blumenfeld, P. C., \& Paris, A. H. (2005). School engagement. In K. A. Moore, \& L. H. Lippman (Eds.), What do children need to flourish? Conceptualizing and measuring indicators of positive development. New York: Springer Science.

Grolnick, W. S., Ryan, R. M., \& Deci, E. L. (1991). The inner resources for school performance: Motivational mediators of children's perceptions of their parents. Journal of Educational Psychology, 83, 508-517. 
Hirschfeld, R. M. A., Klerman, G. L., Gough, H. G., Barrett, J., Korchin, S. J., \& Chodoff, P. (1977). A measure of interpersonal dependency. Journal of Personality Assessment, 41, 610-618.

Kins, E. \& Soenens, B. (2013, September). Generation me and its helicopter parents: A study on parental overprotection in adolescence. Paper presented at the $16^{\text {th }}$ European Conference on Developmental Psychology (ECDP), Lausanne, Switzerland.Klein, M. B., \& Pierce, J. D. (2009). Parental care aids, but parental overprotection hinders, college adjustment. Journal of College Student Retention: Research, Theory and Practice, 11(2), 167-181.

Lamborn, S. D., Mounts, N. S., Steinberg, L., \& Dornbusch, S. M. (1991). Patterns of competence and adjustment among adolescents from authoritative, authoritarian, indulgent, and neglectful families. Child development, 62(5), 1049-1065.

Ledbetter, A. M., \& Vik, T. A. (2012). Parental invasive behaviors and emerging adults' privacy defenses: Instrument development and validation. Journal of Family Communication, 12(3), 227-247.

LeMoyne, T., \& Buchanan, T. (2011). Does “hovering” matter? Helicopter parenting and its effect on well-being. Sociological Spectrum, 31(4), 399-418.

Neeman, J., \& Harter, S. (1986). Manual for the self-perception profile for college students. Unpublished manuscript, University of Denver, Denver, Colorado.

Odenweller, K. G., Booth-Butterfield, M., \& Weber, K. (2014). Investigating Helicopter Parenting, Family Environments, and Relational Outcomes for Millennials. Communication Studies, 65(4), 407-425. 
Padilla-Walker, L. M., \& Nelson, L. J. (2012). Black hawk down?: Establishing helicopter parenting as a distinct construct from other forms of parental control during emerging adulthood. Journal of adolescence, 35(5), 1177-1190.

Parker, G., Tupling, H., \& Brown, L. B. (1979). A parental bonding instrument. British Journal of Medical Psychology, 52, 1-10.

Ritchie, L. D., \& Fitzpatrick, M. A. (1990). Family communication patterns: Measuring intrapersonal perceptions of interpersonal relationships. Communication Research, 17, 523-544.

Robbins, R. J. (1994). An assessment of perceptions of parental autonomy support and control: Child and parent correlates. Unpublished Doctoral Dissertation, Department of Psychology, University of Rochester, 1994.

Ryff, C. D. (1989). Happiness is everything, or is it? Explorations on the meaning of psychological well-being. Journal of personality and social psychology, 57(6), 1069.

Schiffrin, H. H., Liss, M., Miles-McLean, H., Geary, K. A., Erchull, M. J., \& Tashner, T. (2014). Helping or hovering? The effects of helicopter parenting on college students' well-being. Journal of Child and Family Studies, 23(3), 548-557.

Schludermann, E. H., \& Schludermann, S. M. (1988). Children's Report on Parent Behavior (CRPBI-108, CRPBI-30) for older children and adolescents (Technical Report). Winnipeg, MB, Canada: Department of Psychology, University of Manitoba. 
Schreiber, J. B., Nora, A., Stage, F. K., Barlow, E. A., \& King, J. (2006). Reporting structural equation modeling and confirmatory factor analysis results: A review. The Journal of Educational Research, 99(6), 323-338.

Segrin, C., Woszidlo, A., Givertz, M., \& Montgomery, N. (2013). Parent and child traits associated with overparenting. Journal of Social and Clinical Psychology, 32(6), 569-595.

Soenens, B., Beyers, W., Vansteenkiste, M., Sierens, E., Luyckx, K., \& Goossens, L. (2004, July). The 'gross anatomy' of parenting styles in adolescence: Three or four dimensions? Paper presented at the 18th biennial meeting of the International Society for the Study of Behavioural Development (ISSBD), Ghent, Belgium

Wartman, K. L., \& Savage, M. (2008). Parental involvement in higher education: Understanding the relationship among students, parents, and the institution. ASHE Higher Education Report, 33(6), 1-125.

Wilhelm, K., Niven, H., Parker, G., \& Hadzi-Pavlovic, D. (2005). The stability of the Parental Bonding Instrument over a 20-year period. Psychological medicine, 35(03), 387-393. 